\title{
EL CAMPO DE MONTIEL EN LA ÉPOCA DE CERVANTES
}

\section{INTRODUCCIÓN}

En la preceptiva clásica se solía aconsejar que el prólogo era lo último que el autor debía escribir, aunque luego se pusiese como frontispicio de su obra, precisamente porque allí se hacía una declaración de principios o confesión, en la que se dejaba constancia de los factores que habían concurrido en la génesis y desarrollo de la obra.

Mientras que los autores fueron fieles a este principio, los prólogos han sido piezas claves para entender una obra, y comprender al creador, aunque somos conscientes que los investigadores no siempre reparan en este aspecto ${ }^{1}$.

Cuatro puntos hay que tener en cuenta en el prólogo de la primera parte del Quijote, que justifican nuestro trabajo, y la importancia de las fuentes documentales que hemos manejado en la investigación:

1. El Quijote está concebido en la cárcel (Castro del Río, otoño de 1592; Sevilla, finales de 1597); la mayoría de los estudiosos señalan los años finales del siglo XVI (1597), o comienzos del XVII (1602), como fechas de comienzo, teniendo en cuenta que fue un

1 Posteriormente el mismo Cervantes recordará los sinsabores que le ocasionó el prólogo de la primera parte del Quijote, escrito en 1604. «No me fue tan bien... que quedase con gana de segundar con este. De esto tiene la culpa algún amigo de los muchos que en el discurso de mi vida he granjeado, antes con mi condición, que con mi ingenio». Novelas Ejemplares, Prólogo. Cfr. Fernández DE AvellaneDA, A., El Ingenioso Hidalgo Don Quijote de la Mancha, Prólogo. 
período amplio de tiempo en el cual se modificó bastante el proyecto inical ${ }^{2}$.

2. Deliberadamente Cervantes renuncia en su obra a todo aparato crítico y de gran erudición: conocimientos históricos y geográficos, clásicos y humanísticos, literarios y religiosos, tan comúnmente utilizado en esa época, pero mostrando paradójicamente una vasta cultura y profundos conocimientos ${ }^{3}$.

3. Cervantes deja su obra conscientemente imprecisa, para hacerla más grande, más amplia y profunda; al mismo tiempo, la investigación posterior ha tenido que buscar apasionadamente los significados, intuyendo y probando lo que veladamente ocultó su autor ${ }^{4}$.

4. Ante estas vaguedades, sin embargo, hay ocasiones de suma precisión, como cuando afirma, reiterándolo, que D. Quijote cami-

2 "¿Qué podría engendrar el estéril y mal cultivado ingenio mío, sino la historia de un hijo seco, avellano, antojadizo y lleno de pensamientos varios y nunca imaginados de otro alguno, bien como quien se engendró en la cárcel, donde toda incomodidad tiene su asiento y donde todo triste ruido hace su habitación?». Don Quijote, Prólogo parte primera. Así como hay una fecunda literatura de exilio, hay otra importantísima creación artística de prisión (cárceles de berbería, reales, inquisitoriales, de las dictaduras, campos de concentración, etc.), que ha generado unas obras con escasez de recursos materiales y formales, pero con una riqueza de contenidos que han desconcertado a los lectores y oyentes, a través del tiempo.

3 «¿Cómo queréis vos que no me tenga confuso el qué dirá el antiguo legislador que llaman vulgo cuando vea que, al cabo de tantos años como ha que duermo en el silencio del olvido, salgo ahora, con todos mis años a cuestas, con una leyenda seca como un esparto, ajena de invención, menguada de estilo, pobre de conceptos y falta de toda erudición y doctrina, sin acotaciones en las márgenes y sin anotaciones en el fin del libro, como veo que están otros...?». D. Quijote, Prólogo parte primera. Y, sin embargo, muestra unos sorprendentes conocimientos de casi todo. No es nuestro propósito analizar los recursos utilizados por Cervantes en su obra: el "yo" como un personaje más, la reiteración diferenciadora entre el supuesto autor (historiador arábigo) y el supuesto autor ficticio (padrastro), el juego literario entre transcriptor-traductor (morisco) y el amigo anónimo (prólogo), las alusiones personales e intencionales a otros, etc.

${ }_{4}$ Ratificado en dos citas claves, por la ubicación que tienen en la obra, al comienzo y al final: "Yo determino que el señor Don Quijote se quede sepultado en sus archivos de la Mancha hasta que el Cielo depare quien le adorne de tantas cosas como le faltan; porque yo me hallo incapaz de remediarlas, por mi insufiencia y pocas letras, y porque naturalemente soy poltrón y perezoso de andarme buscando autores que digan lo que yo me sé decir sin ellos». D. Quijote, Prólogo primera parte. «Este fin tuvo el Ingenioso Hidalgo de la Mancha, cuyo lugar no quiso poner Cide Hamete puntualmente, por dejar que todas las villas y lugares de la Mancha contendiesen entre si por ahijársele y tenérsele por suyo". D. Quijote, II, 74. Recuérdese que la "veladura" fue un elemento clásico en la obra artística del Renacimiento, así como la "cortina" lo será del Barroco; ambos recursos utilizados para mostrar algo, pero tratando de ocultar parte. Es una manifestación en la que el misterio y la imaginación también son elementos constitutivos para la intelección completa. 
naba por el Campo de Montiel, que sin una intencionalidad expresa es difícil de mantener ${ }^{5}$.

Sin perder de vista estos prenotandos, nuestro propósito se centra en presentar la vida de los pueblos del Campo de Montiel, que por voluntad decidida, Cervantes escoge para situar el origen del Quijote, puesto que aunque no quiso acordarse del «lugar» de la Mancha, sí deseó fijar el comienzo de su historia en el «antiguo y conocido Campo de Montiel», y no sólo fue así de contundente, sino que lo ratifica de nuevo: «y era la verdad que por él caminaba» ${ }^{6}$.

Aunque no analizaremos los significados filológicos del comienzo (octosílabo de un romance antiguo que se encadena con un endacasílabo), y otros aspectos afines, tan debatidos entre los cervantistas de todos los tiempos, queremos dejar constancia de las imprecisiones detectadas en la reciente edición del Profesor Rico, como obra de inmediata actualidad, que recoge los frutos de la última investigación. Para el ilustre académico, el famoso lugar de la Mancha parece que fue elegido «seguramente por azar», y cuya designación la hace coincidir con la existencia de un romance que narraba la muerte de D. Pedro I el $\mathrm{Cruel}^{7}$.

En el mismo sentido localista, M. Carmen Marín asegura, en el volumen complementario de estudios de esa edición, que «DQ se lanza a los campos de Montiel en busca de aventuras ${ }^{8}$; si habla de «campos de Montiel» está haciendo referencia directa a la villa y su ámbito inmediato, y no al partido o gobernación, siendo así que las alusiones cervantinas a ése territorio son en la segunda acepción de comarca, y sólo en una ocasión alude D. Miguel a la villa y no al territorio geopolítico ${ }^{9}$.

En ésta misma edición, refiriéndose a la doble alusión territorial del comienzo de las aventuras, en el capítulo 2, se afirma que «Cervantes interpoló pasajes que confirieron a la trama un alcance mayor..., al tiempo que añadía detalles precisos... la repetición del topónimo del Campo de Montiel ${ }^{10}$. Creemos que esa reiteración a

5 «... en hallar tan sincera y tan sin vueltas la historia del famoso Don Quijote de la Mancha, de quien hay opinión por todos los habitantes del distrito del campo de Montiel que fue el más casto enamorado y el más valiente caballero que de muchos años a esta parte se vió en aquellos contornos». D. Quijote, Prólogo primera parte.

6 Don Quijote, I, 2. No hacemos más referencias a otras alusiones de este terriotrio.

7 D. Quijote de la Mancha. Barcelona 1998, t. I, pp. 35 y 47.

8 Ibid, t. II, p. 19

9 D. Quijote, II, 8.

10 Anderson, E. M., y Pontón, G., «La Composición del Quijote», Ibid, t. I, p. CLXX. 
un espacio geógrafíco concreto no se puede entender sin un marcado interés, por parte de Cervantes, de vincularlo conscientemente a donde lo hizo.

Aunque también queda fuera de nuestro actual propósito, deseamos recoger en muy breves líneas, un hecho, cuando menos, sorprendente. La asociación "Caminos de Cervantes y Sefarad», en su Segundo Congreso Internacional recogió unas ponencias en las que se trataba de demostrar que la comarca zamorana de Sanabria era el lugar en el que hay que situar la obra de Miguel de Cervantes, por estar la cuna de su linage en un lugar de las montañas de LeónZamora (Cervantes de Sanabria). En esa clave se reinterpreta todo el Quijote ${ }^{11}$.

Creemos que esta línea de investigación es un camino equivocado y un esfuerzo inútil el seguido por el estimado Prof. D. Leandro Rodríguez. Nada mejor que recordar las palabras que el propio Cervantes pone en boca de Cide Hamete, quien, aprovechando que aconseja a la pluma con la que escribió la obra, censura a Fernández de Avellaneda, fingido autor de Tordesillas, y dice «que deje reposar en la sepultura los cansados y ya podridos huesos de Don Quijote, y no le quiera llevar, contra todos los fueros de la muerte, a Castilla la Vieja, haciéndole salir de la fuesa, donde real y verdaderamente yace» ${ }^{12}$.

\section{El marco geográfico del CAMPo DE Montiel}

\subsection{Concepto de Campo de Montiel}

El Campo de Montiel es una altiplanicie, de las más altas de la península; sin embargo, fisiográficamente esta platarforma geológica comprende más territorio y pueblos de los que históricamente se han incluído dentro de los límites asignados al Campo de Montiel por tratadistas y viajeros.

La extensión de esta altiplanicie es de $3.300 \mathrm{~km}^{2}$, aprox., levemente ondulada en su horizontalidad por efectos de la erosión, e inclinada estructuralmente hacia el Este, llegando a sobrepasar los

11 El Congreso se celebró en Zamora, Braganza, Puebla de Sanabria y Benavente, en julio de 1994. Las Actas se publicaron en Zamora, en 1995. Para nuestro tema, cfr. H. Fuentes Gutiérrez, «La patria de Miguel de Cervantes. Finalmente al descubierto la patria de Miguel de Cervantes. Cuna de su linage», pp. 3948; G. RODRÍGUEZ DE LEMA, "Flora y fauna de Sanabria en el Quijote», pp. 49-53; L. Rodríguez, "El Ingenioso Hidalgo Don Quijote de Sanabria», pp. 63-120; ÍDEM, «Bergança y Don Quijote. Una persona con dos interiores», pp. 137-148.

12 D. Quijote, II, 74. 
$1.000 \mathrm{~m}$. de altitud (El Bonillo, 1068; El Ballestero, 1105), mientras que en el borde Oeste alcanza los $720 \mathrm{~m}$. (Argamasilla de Alba), y siendo su altitud media de $850 \mathrm{~m} .{ }^{13}$.

Tiene gran importancia hidrológica por sus ríos Azuer, Guadalén, Guadalmena, Jabalón... y el padre Guadiana, que en Ruidera tiene su origen; también destacan las aguas subterráneas como lo demuestra la explotación del acuífero de esta comarca.

Desde el punto de vista pluviométrico y climático, escogemos a Villanueva de los Infantes, centro histórico y administrativo del Campo de Montiel; tiene un clima templado, cuya media anual es de $13^{\circ}$ (en invierno alcanza una media entre $4^{\circ}$ y $5^{\circ}$, y en verano llega la media a $26^{\circ}$ ). Las precipitaciones anuales son de $481 \mathrm{~mm}$., caídas fundamentalmente a finales de otoño, y desde marzo hasta mayo.

La comarca del Campo de Montiel está dentro del país manchego, pero posée características propias y peculiaridades específicas que la diferencian de las otras comarcas limítrofes, aunque, en unión con ellas, participa de elementos comunes que la vinculan a la madre Mancha, de la que recibe el ser natural y la existencia histórico-administrativa.

Su enclave privilegiado en el cruce de importantes vías le hizo ser, desde antiguo, un espacio por el que cruzaban hombres, ideas y mercancías. Volver a poseer ahora el conocimiento de ese pasado, reivindicando la importancia que tuvo su situación, no sólo debe ser intento de recuperar la dignidad histórica perdida, sino que también tiene que ser el comienzo de nuevas estrategias de actuación presente, para preparar el inmediato mañana ${ }^{14}$.

Tratando de señalar unos límites aproximativos, tenemos que «el ámbito del famoso Campo de Montiel mencionado por Cervantes, comprendía desde el Ayozo, bastante al Sur de Argamasilla de Alba, y desde cerca de Manzanares y Membrilla hasta Beas, Santisteban

13 Planchuelo, G., Estudio del Alto Guadiana y de la Altiplanicie del Campo de Montiel. Madrid 1954. Nueva ed., Ciudad Real 1992; TERÁN, M., y SolÉ, L., Geografía Regional de España. Barcelona 1969, pp. 192 y 370; VARIos, Geografía de España. Barcelona 1991. Planeta, t. 7: Extremadura, Castilla-La Mancha y Madrid, pp. 301-302.

14 Rodríguez Castillo, J., D. Quijote por el Campo de Montiel (como debe ser). Villanueva de los Infantes 1999. Conscientes de que urge una reactivación de la comarca, así se expresan los autores de la citada Geografía de España de Planeta: «El Campo de Montiel constituye una zona de fuertes resonancias históricas y culturales que reclaman mayor reanimación. El plan Nacional de Interés Comunitario ha incluido, en la provincia de Ciudad Real, a Villanueva de los Infantes como uno de los núcleos prioritarios de inversión. Tratándose de un importante conjunto histórico artístico se pretende recuperarlo del estancamiento en que permanece...», t. 7, p. 302. Bien, pero ¿qué, quién, cuándo, cómo se hace? El tiempo transcurre y todo parece desesperadamente quieto. 
y Montizón, en la provincia de Jaén, llegando por levante a abarcar casi todas las Lagunas de Ruidera, el pueblo de la Osa de Montiel, la ermita de San Pedro, la Cueva de Montesinos y el Castillo de Rochafrida» ${ }^{15}$.

\subsection{Los pueblos del Campo de Montiel}

El territorio del Campo de Montiel corresponde fundamentalmente a suelo de la provincia de Ciudad Real y algo de la de Albacete; en el Antiguo Régimen constituyó el Partido, administrativo y judicial, de este nombre, por agrupar a pueblos pertenecientes a la jurisdicción de la Orden Militar de Santiago ${ }^{16}$.

En la documentación del siglo XVI, el Campo de Montiel, de la provincia de Castilla, estaba formado por veintidós pueblos, a saber ${ }^{17}$ : Albaladejo (Albaladejo de los Frailes), Alcubillas, Alhambra (Herrera de los Montes Negros), Almedina, Cañamares, Carrizosa, Castellar de Santiago (Castellar de Santiago de la Mata), Cózar, Fuenllana, Membrilla (La Membrilla del Tocón), Montiel, Ossa de Montiel (La Osa o Lahossa), Puebla del Príncipe (La Puebla de Montiel o La Puebla del Príncipe), Santa Cruz de los Cáñamos, La Solana, Terrinches, Torre de Juan Abad (Villa de Santiago o la Torre Abad), Torrenueva, Torres (Torres de Montiel), Villahermosa (Pozuelo), Villamanrique (Balmontejo de la Sierra) y Villanueva de los Infantes (Jamila y La Moraleja).

A comienzos del siglo XVIII, Beas y Chiclana figuran como pueblos integrantes del partido de Infantes, y así se sigue ratificando en la centuria siguiente cuando se haga la nueva división territorial de provincias y partidos ${ }^{18}$; por causa del despoblamiento entonces se da a Torres por desaparecido ${ }^{19}$.

15 Aguirre de Prado, L., Geografía del Quijote. Madrid 1976, p. 39.

16 Para el nacimiento y primera configuración del partido de Montiel, en días de la reconquista, con los términos, villas, despoblados, encomiendas y fortalezas que tenía, etc., CHAvES, B. DE, Apuntamiento legal sobre el dominio solar de la Orden de Santiago en todos sus pueblos, s.l.n.a. [Madrid 1740], pp. 16v-19, 41-41v, 191v194, 202v-203 (mapa). Ed. Facsímil. Barcelona 1975.

17 González, T., Censo de Población de las Provincias y Partidos de la Corona de Castilla en el siglo XVI. Madrid 1829, p. 74; Censo de Castilla de 1591. Vecindario. Madrid 1984, p. 195. Conocido como el de los "Millones», porque para este servicio se hizo, para enjugar los gastos de la Gran Armada, en las Cortes de 1588-1590; el impuesto era obligatorio para todos los grupos sociales - civiles (nobles, hidalgos, pecheros), y eclesiásticos (seculares y regulares)-, excepto los religiosos descalzos de San Francisco, que por eso se anotan aparte. Fue muy impopular.

${ }_{18}$ Censo de Campoflorido, o Vecindario General de España. Madrid 1995, p. 19; Madoz, P., Diccionario Geográfico-Estadístico-Histórico de España y sus posesiones de Ultramar. Madrid 1846, t. V, p. 373.

19 Madoz afirma que tiene «2 vecsinos y 7 almas». Cfr. Diccionario, o. c. Ma- 
Si el criterio de pertenencia al Campo de Montiel fue la cercanía espacial y haber pertenecido a la Orden de Santiago, ambos pueblos están próximos y fueron de la jusrisdicción de esa Orden Militar. Además, la Encomienda de Montizón, perteneciente a esta circunscripción, sufragaba todos los gastos del culto de la parroquia de Chiclana, que eclesiásticamente dependía de la Vicaría de Beas; en la Relación de Villanueva de los Infantes y de Beas, se asegura que las alcabalas y otros impuestos del partido de Segura de la Sierra se cobraban en Infantes ${ }^{20}$. Sin embargo, en las Relaciones de estos pueblos de Jaén, afirmando que pertenecen a la Orden de Santiago, no confirman que su integración al Campo de Montiel, como lo hacen otros ${ }^{21}$.

Otra dificultad seria es que mientras que los pueblos del Campo de Montiel pertenecían al arzobispado de Toledo, Beas y Chiclana dependen de la mitra de Cartagena.

Teniendo en cuenta la complejidad geohistórica y político-administrativa que ha sufrido el partido y Campo de Montiel, por la variación de sus límites, es necesario un estudio serio y minucioso para fijar el perímetro de sus fronteras y el ámbito de su jurisdicción en su evolución temporal. No obstante esto, para nuestro estudio nos quedamos con el listado de pueblos antes citado en los documentos del Quinientos, coetáneos a los días de Cervantes, y por tanto, la división y pertenencia que él conoció.

\section{El CAmpo de Montiel en las RElaciones topográficas}

\subsection{Importancia de estas fuentes documentales}

En los años centrales del reinado de Felipe II cobra cuerpo un ambicioso proyecto, convirtiéndose en la obra cultural más ambiciosa de todo el siglo XVI español, por extensión y trascendencia. Nos referimos a las Relaciones Topográficas. Fueron concebidas con la doble finalidad de conocer la realidad concreta de los pueblos y de reunir amplia y segura información para poder escribir, con garantía y datos, una Historia General:

drid 1849, t. XV, p. 101. Tampoco figuraba ya en el Vecindario de Ensenada. Madrid 1991 , t. I, pp. 568-569,

20 Relación de Villanueva de los Infantes, núm. 10; de Beas, núm. 8.

21 Transcripción de L. R. Villegas y R. García Serrano, en Boletín de Estudios Giennenses (Jaén), XXII, núms. 88-89 (1976), 35-80 (Beas), y 121-131 (Chiclana). Existe otra versión, Murcia 1992, de A. Cebrián y J. Cano. Originariamente integradas en el partido de Montiel, cfr. Chaves, B., Apuntamiento, o. c., p. 41. 
"Por haber entendido que hasta ahora no se ha hecho ni ay descripción particular de los pueblos de estos reinos, cual conviene a la autoridad y grandeza de ellos, habemos acordado se haga la dicha descripción y una historia de las particularidades y cosas notables de los dichos pueblos» ${ }^{22}$.

El interrogatorio al que tenían que responder los pueblos era un amplio cuestionario en el que se inquirían datos sobre asuntos geográficos, históricos, económicos, religiosos, demográficos, artísticos, etc. Recababan información sobre el enclave de la localidad, las vías de comunicación, las instituciones y la jurisdicción; preguntaban la calidad del suelo y la riqueza del subsuelo; sobre caza y pesca, especies y abundancia; lo que producían, lo que dezmaban y de lo que carecían; que describiesen el hábitat común y los edificios notables.

No se olvidaban de informarse sobre las ferias y los mercados; también recogían datos del clima y del tiempo, de los habitantes y de la curva poblacional, con la tendencia en esos momento, y las razones que la explicasen; número de vecinos, sus categorías y nivel económico. Querían saber si el lugar era sano o enfermo, antiguo o moderno, aislado o pasajero... y todo aquello que los naturales considerasen importante, pasado o presente, para un mayor y más completo conocimiento del lugar ${ }^{23}$.

Inicialmente se hizo una pequeña experiencia con algunos pueblos del obispado de Coria. Definitivamente el proyecto se materializó en dos interrogatorios de 57 y 45 preguntas, redactados en 1575 y 1578, respectivamente, que fueron los que, en dos fases, se remitieron sucesivamente a las diferentes autoridades territoriales ${ }^{24}$.

La importancia de las Relaciones para la obra del Quijote estriba en que la información que facilitan los redactores de las villas de la Mancha - abundante, fiel, detallada - corresponde a la época cervantina; los pueblos descritos en la obra filipense cuentan lo que

22 Archivo General de Simancas, Estado, leg. 157. La Instrucción se firmó en El Pardo, el 27-X-1575. Esa finalidad de recabar la información que piden para hacer una Crónica General o Historia de los pueblos de España queda recogido en el preámbulo de la mayoría de las respuestas. Referente a la coincidencia de las fechas, un mes antes Cervantes había partido del puerto de Nápoles, rumbo a España, en la galera "La Sol», cayendo prisionero en manos de los berberiscos, el 26 de Septiembre.

${ }_{23}$ Un amplio estudio con la historia de estas fuentes, datos y cifras, en CAMPOS, F. J., La Mentalidad en Castilla la Nueva en el siglo XVI (Religión, Economía y Sociedad según las 'Relaciones Topográficas' de Felipe II). San Lorenzo del Escorial 1986, XV + 478 pp., 27 X 21,5 cms.

24 Miguélez, M., Catálogo de los Códices Españoles de la Biblioteca del Escorial. Relaciones Históricas. Madrid 1917, t. I, pp. 263-268 y 273-276. En los pliegos de respuestas de los pueblos, algunos de ellos incluyeron el formulario impreso al que habían contestado, cfr. Relaciones de Monhernando (1578) y de Toledo (1575). 
Cervantes vió en su cruzar y vivir en esta tierra. Ambiente de un ser y de un existir real que, posteriormente, se incoporaron a las páginas de la obra literaria con valor y entidad propia ${ }^{25}$.

El proceso de redacción de las Relaciones es simultáneo a los primeros meses de la prisión de Cervantes en Argel. Regresa a España en Octubre de 1580 y comienza su azarosa carrera en la Administración y su agitada vida personal, mezclándose esa tensión con la apacibilidad creadora y el desgarro de los desamores; además, nos encontramos con el misterio de conocer su ocupación durante algunos años, todavía en penumbra para la moderna investigación.

Cuando las aventuras de D. Quijote van llenando abundantes pliegos, los también numerosos cuadernillos que remiten las autoridades municipales y territoriales, estaban llegando al Monasterio del Escorial, cerca del rey, y no a Simancas, porque probablemente el monarca pensaba utilizar la ingente información allí contenida en algún proyecto inmediato.

La realización del programa de las Relaciones sólo obtuvo un éxito parcial; respondieron 715 pueblos pertenecientes mayoritariamente a Castilla la Nueva; por causa de señorío, jurisdicción y dominio territorial, también respondieron algunos pueblos correspondientes a localidades de Jaén, Cáceres y Murcia; muy escasas y testimoniales son las respuestas de pueblos de Alicante, Badajoz, Ávila y Salamanca ${ }^{26}$.

El agravamiento de los problemas de la Corona en las tierras y los mares del vasto imperio hispánico, a los que había que acudir con urgencia y empeño, hizo que este ambicioso proyecto de las Relaciones fuese perdiendo fuerza entre los objetivos pendientes hasta que, definitivamente, se archivaron los pliegos con las respuestas recibidas en la recién fundada Biblioteca Laurentina, donde, encuadernados posteriormente, después de perderse las relaciones de algunas villas, se han conservado hasta hoy ${ }^{27}$.

25 Para una abundante y actualizada bibliografía sobre las Relaciones, CAMPOS, J., «Las Relaciones Topográficas de Felipe II: perspectivas de unas fuentes históricas monumentales sobre Castilla la Nueva en el siglo XVI», en La Ciencia en el Monasterio del Escorial. Actas del Simposium. San Lorenzo del Escorial 1994, t. I, pp. 381-429; nuevamente ampliado, en «Las Relaciones Topográficas de Felipe II. Fuentes jurídicas indirectas: valoración y perspectivas", en Espacios y Fueros en Castilla-La Mancha (siglos XI-XV). Una perspectiva metodológica. Madrid 1995, 635677. Ed. de J. Alvarado Planas.

26 Campos, F. J., La Mentalidad, o. c., pp. 8-9.

27 Hay constancia de que el 24-XI-1583, Juan de Herrera cogió las de Almagro y Corral de Almaguer para enseñárselas al rey. Cfr. Relaciones de La Puebla de Almuradiel (Ms. J.I.15, fol. 47v), y Quintanar de la Orden (Ms. J.I.14, fol. 704v), respectivamente. 
El siglo XVII trajo otras inquietudes y las Relaciones Topográficas se olvidaron en la Biblioteca Laurentina ${ }^{28}$, hasta que en la segunda mitad de la pasada centuria muy tímidamente comenzaron a suscitar interés en D. Fermín Caballero, que fue el que dió a conocer la riqueza de estas fuentes documentales ${ }^{29}$.

\subsection{Los pueblos del Campo de Montiel en las Relaciones}

En la Relación de Villanueva de los Infantes se incluye al final un mapa en folio del Campo de Montiel, que es una joya, porque sólo con otro mapa de Pastrana y su tierra, también en folio, son las ilustraciones de tipo cartográfico contenidas en los códices originales ${ }^{30}$.

Según el mapa, veintitrés son los pueblos que integran el Campo de Montiel: Albaladejo, Alcubillas, Alhambra, Almedina, Cañamares, Carrizosa, Castellar de Santiago, Cózar, Fuenllana, Membrilla, Montiel, Ossa de Montiel, Puebla del Príncipe, Ruidera, Santa Cruz de los Cáñamos, La Solana, Terrinches, Torre de Juan Abad, Torrenueva, Torres, Villahermosa, Villamanrique y Villanueva de los Infantes. Al final de la Relación de Villanueva de los Infantes se repite el listado de «los pueblos que hay en la gobernación del Campo de Montiel»; se incluyen todos los pueblos, menos Ruidera ${ }^{31}$.

De todos los pueblos, que eran villas entonces, existen Relaciones; no las hay de las aldeas, en nombre de las cuales facilitaron algunos datos sus correspondientes cabeceras: Carrizosa, aldea de Alhambra; Torres, Cañamares y Santa Cruz de los Cáñamos, aldeas de Montiel. Torres ya desaparecido ${ }^{32}$.

El desajuste de este listado (23 pueblos) con los nombres consignados en los Censos antes citados del siglo XVI (22 pueblos) se debe a que en el mapa se incluye Ruidera, pero no existe Relación, aunque el lugar estaba vinculado a la Orden y Maestre de Santiago, que allí tenía propiedades ${ }^{33}$.

\footnotetext{
28 Mss. J.I.12 al 18, y L.II.4. Ocho volúmenes.

29 Historiografía, en CAMPos, F. J., La Mentalidad, o. c., pp. 14-37.

30 Ms. J.I.14, f. 344 (Campo de Montiel); J.I.15, f. 381 (Pastrana). Existe un tercer dibujo (f. 406 de este último Ms.) correspondeinte al Sto. Cristo de Albalate, en la Relación de Albalate de Zorita.

31 Ms. J.I.14, f. 342v; cfr. nota 33.

32 Cfr. nota 17.

33 Madoz asegura que antes de que el arquitecto real, Juan de Villanueva, levantase la fábrica de pólvora (1770-1780), sólo había 5 ó 6 casas. Diccionario, o. c. t. XIII, p. 595. Para el tema del Heredamiento de Ruidera - pastos y molinosy su vinculación a la Orden y Maestre de Santiago, cfr. Relaciones de Alhambra,
} 
Para dificultar las cosas, también hay que dejar constancia de que en la Relación de Almedina se asegura que «el Campo de Montiel, que es una gobernación de quince villas e tres aldeas...» ${ }^{34}$. Según ésto, ¿cuáles quedarían fuera de ese cómputo y listado? En el último folio de esta Relación, núm. 54, aseguran que «la villa de la Puebla del Príncipe, Villamanrique, La Torre de Juan Abad e la villa de Cózar, que todos son pueblos pequeños... los cuales son de la Orden de Santiago en este partido del Campo de Montiel, e por ser pueblos nuevos no se sabe dellos cosa que digna sea de escribir» ${ }^{35}$

Como desde el punto de vista geográfico la altiplanicie comprende a más pueblos de los que integran el antiguo Campo de Montiel, y a su vez, algunas localidades de las tierras montieleñas no forman parte de la altiplanicie geográfica, surge la confusión; en el estudio pionero del Prof. Planchuelo, con alguna incursión a las Relaciones Topográficas, afirma:

«En la lista anterior [basado en las Relaciones] figuran La Membrilla, Torrenueva [por error se olvida de citarla] y El Castellar, que si bien eran del Campo de Montiel, no entran dentro de la altiplanicie que estudiamos. En cambio, Villanueva de la Fuente (hecha villa por Felipe II, en 1565) con 299 vecinos y El Bonillo con 1075 (en 1575), no figuran en la lista, lo mismo que Munera, Viveros, Povedilla, el Ballestero y Robledo, por no pertenecer à aquel Campo, si bien caen dentro de la comarca objeto de esta tesis» ${ }^{36}$.

En el pasado siglo ya hemos visto que se incluyeron indebidamente dos pueblos de Jaén al Campo de Montiel; también se agregaron a este partido otras trece localidades, basándose en que eran jurisdicción de la Orden de Santiago, pero tratándose de una vinculación meramente administrativa, sin identidad geofísica: Altillo,

núm. 22, y de la Solana, núm. 20. Ruidera pertenecía a la jurisdicción de Alcázar de San Juan; en las lagunas existían unos molinos harineros pertenecientes al Maestre de Santiago y, tras unas contiendas con los vecinos de Argamasilla, se llegó a una concordia entre el Prior de San Juan (Alcázar) y la Mesa Maestral (Infantes), por la cual aquellos terrenos de pastos y los molinos pasaban a poder del Prior, a cambio de un canon que había que satisfacer en Villanueva de los Infantes, y los molinos serían transformados en fábrica de pólvora.

34 Ms. J.I.14, f. 332, núm. 4.

35 Ibid, f. $335 \mathrm{v}$. Si se refiriesen a estos cuatro pueblos nuevos en la alusión del comienzo, sí se completaría el número global de veintidós.

36 Estudio, o. c., pp. 132-133. Otra prueba contemporánea de que eran pueblos que estaban ubicados en la plataforma, pero no integraban el Campo de Montiel, es el hecho de que de ninguno de ellos exista Relación, hecho bastante inadmisible si las hay de todos los demás; cuesta aceptar que el Gobernador del Partido, al reunir las respuestas de las otras villas, no hubiese urgido a los morosos el cumplimiento de la orden real. 
Campo de Criptana, Socuéllamos y Tomelloso (Ciudad Real); Hinojoso de la Orden, Horcajo de las Torres, Santa María de los Llanos y Villamayor de Santiago (Cuenca); Cabeza Mesada, Miguel Esteban, Quintanar de la Orden, El Toboso y Villanueva de Alcardete (Toledo) ${ }^{37}$.

\subsection{Visión panorámica de los pueblos del Campo de Montiel}

Según el título de este epígrafe, no nos detendremos en hacer un amplio y minucioso desarrollo; no es el momento, ni la ocasión. Daremos una visión general de todas y cada una de las dieciocho villas que integraban el Campo de Montiel, excluyendo las aldeas, de las que no existen Relaciones. Todos son conscientes de que forman parte del Campo de Montiel, y lo repiten infinidad de veces al hablar de la ubicación, de la administración civil y religiosa, de los bienes comunales, de los caminos, etc.

Para no repetir datos conocidos por muchos, y fácilmente asequibles al investigador, nos detendremos brevemente en señalar lo particular y propio de cada pueblo, porque así lo creían y destacaron los redactores del cuestionario enviado en nombre del rey, por el Señor Gómez de Velasco, caballero de la Orden de Santiago, Gobernador y Justicia Mayor del Partido del Campo de Montiel ${ }^{38}$.

Preferimos recoger información del vivir cotidiano de estas gentes y estos pueblos, que es lo visto por Miguel de Cervantes en sus viajes y permanencias en tierras de la Mancha, en la mayoría de los casos con sus mismas palabras, por expresivas, y buen castellano de la Alta Edad Moderna ${ }^{39}$.

Primeramente debemos afirmar que estamos ante unas respuestas mayoritariamente excelentes, tanto por la amplitud y calidad del contenido, como por la información que facilitan; fueron redactadas en Diciembre de 1575, entre los días 1 (las de Castellar de Santiago y La Solana), y el 27 (las de Ossa de Montiel).

Al final de este trabajo se incluye un apéndice en el que se recogen ordenada y sistemáticamente los datos puntuales y las cifras

37 Madoz, P., Diccionario, o. c., t. V, p. 373.

38 Transcripción del manuscrito escurialense hecha por C. VIÑas y R. PAZ, Relaciones de los Pueblos de España ordenadas por Felipe II. Ciudad Real. Madrid 1971. Para la Ossa de Montiel, Relaciones Topográficas de los Pueblos del Reino de Murcia. Murcia 1992.

39 Para no abrumar con reiteradas llamadas a fuentes documentales tan concretas, y tan citadas, a continuación del nombre de cada pueblo indicamos las referencias de los manuscritos y de las transcripciones; en cada tema específico, indicamos el número de la respuesta de la respectiva Relación. 
exactas sobre jurisdicción, vecinos, iglesias y ermitas, diezmos y producciones, votos y fiestas, hospitales, caminería, etc.

\subsubsection{Albaladejo (Ms. J.I.14, ff. 284-291; Transc., pp. 1-12)}

- Comienza la Relación en sentido cristiano vinculando la fecha del calendario al año del nacimiento de Nuestro Señor Jesucristo (preámbulo).

- Su nombre y pertenencia es Albaladejo de los Frailes de la Orden de Santiago; pueblo antiguo (preámbulo, núms. 1 y 2).

- La villa es antigua (núm. 2); está poblada por labradores, aunque las tierras no son de mucho pan llevar, porque algunas son delgadas; tierras de calores y cansadas, por tener esta villa muy poco término y no tener para ensancharse para abrir de nuevo labores. De todo hay poco por ser tierra muerta, estéril y estrecha (núms. 26 y 45).

- Como dato valioso tenemos el de los precios de algunos productos. Por esos años, el trigo valía entre 7 y 8 rs./fan.; la cebada y el centeno, entre 4 y 5 rs./fan. ${ }^{40}$ (núm. 26).

- Las casas de esta villa están hechas y se hacen de piedra, barro y tapiería de tierra; en algunas casas, el tapial lleva alguna costra de cal. Se cubren con madera de pino de sabina y con teja. Todos los materiales hay y son del contorno, menos la madera, que la traen de Alcaraz, Segura y del término de Montiel. Como no hay hombres ricos, los edificios de casas son ruines (núm. 35).

- La población aumenta; viven del trabajo del campo porque no tienen otros tratos. Algunos son oficiales de herreros, sastres, zapateros, y no hay vecino hidalgo ninguno; muchos son pobres y no pueden hacer casas, viviendo de alquiler (números 39,40 y 42 ).

- La iglesia tiene por advocación al señor Santiago, y tienen dos ermitas: de San Juan y de San Sebastián (núms. 49 y 51).

- A dos tiros de ballesta de la villa pasa un camino real por el que cruza mucha gente y arrieros que van y vienen de la Andalucía a la Mancha y reino de Valencia (núm. 55).

40 El real equivalía a 34 maravedíes. La fanega tenía 12 celemines y 55 litros; el celemín equivale a 4 cuartillos, 4,6 litros y $537 \mathrm{~m}$. cuadrados. Como medida agraria, la fanega era un espacio de tierra de 64,5 áreas, y el área equivalía a 100 m. cuadrados. Es medida muy variable en las distintas regiones españolas. 
3.3.2. Alcubillas (Ms. J.I.14, ff. 326-330v; Transc., pp. 25-30)

- Es pueblo antiguo; aldea de Montiel, hasta que se redimió, en 1539, sirviendo al emperador con la cantidad de $520.000 \mathrm{mrs}$. (núm. 23).

- La tierra es fría y de muchos hielos; rasa y de pocos montes; la tienen por enferma (núm. 17).

- Es una villa sin término, salvo una dehesa boyal; en cuanto al pasto, aprovechan y gozan sus ganados de los pastos y labor de los términos de Montiel, Alhambra y Torre de Juan Abad, por ser términos comunes del Común (núms. 24 y 25).

- La iglesia es de cal y canto buena parte de ella; en esos años se está reedificando; los materiales se traen de fuera, especialmente la piedra. Los demás edificios de las casas de los vecinos se hacen de tierra y madera, salvo los cimientos que son de piedra, hasta una altura de 7 u 8 piés ${ }^{41}$. Está dedicada a Sta. María Magdalena, y tienen tres ermitas: de Ntra. Sra. de la Carrasca, de San Ildefonso y de San Sebastián (núms. 48 y 51).

- La población está estancada; los vecinos son campesinos y viven de labrar la tierra y de criar ganado; habrá una docena de personas que tienen suficiente de comer, todos los demás son gente pobre (núms. 39 y 42).

- El pueblo es lugar pasajero de los que van de Sevilla a Toledo y Madrid (núm. 55).

\subsubsection{Alhambra (Ms. J.I.14, ff. 345-353; Transc., pp. 31-45)}

- También cominezan sus redactores con la invocación religiosa al año del nacimiento de Ntro. Señor Jesucristo (preámbulo).

- El pueblo es muy antiguo; antes se llamó Herrera de los Montes $\operatorname{Negros}^{42}$ (núm. 1; La Solana, núm. 56). De la época

41 Medida de longitud que equivalía a $28 \mathrm{cms}$., aprox. y de muy variadas dimensiones en las regiones. Un pié cuadrado equivalía a $776 \mathrm{cms}$. cuadrados; cúbico, 26,6 cms. cúbico.

${ }_{42}$ En los poemas que los Académicos de Argamasilla dedicaron a D. Quijote, supuestamente encontrados en una caja de plomo -posible alusión crítica de Cervantes a los polémicos plomos del Sacromonte granadino, descubiertos pocos años antes-, en el soneto del Paniaguado a Dulcinea, habla de la "gran Sierra Negra». D. Quijote, I, 52. En la edición de J. García Soriano y J. García Morales sugieren si se referirá a Sierra Morena, cfr. p. 846; en la reciente edición de F. Rico, se afirma que, efectivamente, es Sierra Morena, utilizado como hipérbole, cfr. t. I, 
romana tienen muchos vestigios (estatuas, inscripciones, monedas, etc.) (núms. 2 y 36 ).

- Es una de las tres cabeceras que tiene el partido del Campo de Montiel; la segunda, porque en las juntas del Común, habla, firma y se sienta, después de Montiel (núm. 4).

- Está situada en lo alto de un cerro; la subida es áspera por todas partes, y tiene falta de agua. Es villa más fría que caliente, y más enferma que sana, por causa de un arroyo que pasa al pié del pueblo con poca agua porque se recoge en una serna de tierras labrantías donde se encharca (núm. 17).

- Es tierra abundosa de encinas, robles, retamas y otras matas de monte bajo de los que se proveen, aunque por el mucho desorden que se tiene en el trato con los montes van en disminución; tiene algo de caza (conejos, perdices, liebres, lobos, zorros y venados) (núm. 18).

- Se coge trigo, cebada y centeno en cantidad, y se crían en el término cantidad de ganados cabríos y lanares, y algunos vacunos y porcunos; es también tierra en la que se coge cantidad de vino (núm. 26).

- La inmensa mayoría de sus habitantes son labradores pobres y hombres buenos. El sitio se despuebla por ser áspero y trabajoso para vivir en él; se van a lugares de la comarca donde viven con menos esfuerzo (núms. 39 y 42).

- Sobre los ríos Carrizosá, Azuer y Artillo, hay tres puentes pequeños de cal y canto hechos a costa del Común de las villas del partido, para paso del camino real que va de esta villa a Vva. de los Infantes, Granada y otras partes. Lo mismo en el puente del Puerto de Vallehermoso sobre el Azuer en el camino real de Vva. de los Infantes a La Solana (núm. 22).

- Tiene una iglesia de San Bartolomé, labrada en piedra, con estatuas antiguas de mármol con inscripciones, y dos ermitas: de San Benito y de Sta. Catalina; en el contorno del pueblo hay cuatro ermitas: de Sta. María de Flores, Ntra. Sra. de la Carrasca (Carrizosa), Ntra. Sra la Blanca (Ruidera) y San Antón (núms. 36, 48 y 51).

- Tiene un pequeño grupo de familias hidalgas, cuyos privilegios y exenciones, son los que esta clase goza: no les echan huéspedes, ni les reparten servicios ni otros pechos, ni pueden ser ejecutados o expropiados - armas, castillos o soldados- por deudas civiles, gozando también de las demás exen-

p. 593. Quede constancia aquí de esta otra referencia de fuentes coetáneas, en un territorio del Campo de Montiel, cuya zona se ha conocido también como Sierra de Alhambra, aunque de extensión y dimensiones pequeñas. 
ciones que tienen los hidalgos de Castilla, según sus fueros y leyes (núm. 40).

\subsubsection{Almedina (Ms. J.I.14, ff. 332-336; Transc., pp. 55-61)}

- Muy detallistas fueron los redactores de esta Relación porque en cuanto a su situación geoadministrativa, aseguran que la villa está fundada en el reino de Toledo, en la provincia que llaman Campo de Montiel, que es una gobernación de quince villas y tres aldeas, situada entre la Mancha y la Andalucía, Tierra de Alcaraz y Orden de Calatrava (núm. 4).

- Se enorgullecen de que la villa tiene abundancia de agua, dulce y salobre, no de pozos, porque el pueblo está fundado sobre un cerro de peñas, sino de dos fuentes. Una a la parte del cierzo, con pilar, al pié de donde está fundada la población; fuente de agua dulce, delgada y saludable; tan abundante, que de ella salen continuamente dos caños del grosor del brazo de un hombre. La otra, al mediodía, salobre, de un caño y menos caudal, con pilar para abrevar los ganados (núm. 23).

- Las tierras del pueblo son pobres, y los vecinos viven de labor de los campos, pero no podrían vivir si no saliesen a trabajar en los términos de otras villas, como Montiel y la Torre de Juan Abad. No tienen ganado lanar, y poco de las otras especies (núm. 26).

- La población está estancada; no puede crecer el pueblo porque el lugar donde está edificado no permite construir nuevos edificios (núm. 39).

- Tienen una iglesia dedicada a Ntra. Señora y una ermita de la Magdalena que fue mezquita, según se aprecia por su arquitectura; en el término tienen otras cuatro ermitas: de San Cristóbla, San Nicasio, San Sebastián y Sta. Quiteria.

3.3.5. Castellar de Santiago (Ms. J.I.14, ff. 300-301; Transc., pp. 191-194).

- Es un pueblo nuevo; lo fundaron un grupo de personas procedentes de la Serranía de Cuenca, hará 30 años, en torno a 1545; es villa desde 1563 en que sirvió a S.M. con 5000 duc. ${ }^{43}$

43 El ducado equivalía a 374 maravedíes, o 34 reales. 
- Tiene buen sitio y asiento; es templada y está al pié de Sierra Morena, por eso es montuosa y áspera, y sana (núms. 17 y 32).

- Es lugar abundoso en leña; hay muy cerca y alrededor muchas encinas, robles, jarales, monte pardo y matarrubia; también es tierra de mucha caza, porque se crían perdices, conejos, liebres, ciervos, jabalíes y algunos osos (núm. 18).

- Las casas son de tapiería de tierra plena porque no hay yeso ni otros materiales; de madera se proveen de la Sierra de Alcaraz (núm. 35); la población aumenta (núm. 39).

- Para ser una población pequeña de 370 casas (= vecinos), tiene una alta tasa de hidalgos, que llegan hasta 30 casas (= vecinos) (núm. 39).

- Aumenta la población, a pesar de ser pueblo pobre (núm. 39); no hay tratos ni granjerías, sino que la gente vive de su trabajo y labor en el campo (núm. 42).

- Tiene una iglesia cuyo titular es Sta. Ana (núm. 48).

\subsubsection{Cózar (Ms. J.I.14, ff. 323-325V; Transc., pp. 213-216)}

- También es un pueblo nuevo, y el único del Campo de Montiel que no paga terzuelo ${ }^{44}$ a la mitra de Toledo (núm. 2); era aldea de Montiel, pero en 1554 el emperador la hizo villa por haberle servido con $1.305 .008 \mathrm{mrs}^{45}$ (núm. 3).

- Es tierra llana, fina y sana (núm. 17); tiene cerca cantidad de esparto y jara (núm. 18); también es abundante en agua dulce, sacada de buenos pozos que tienen en las casas, a 4 , $6 \mathrm{u} 8$ estados $^{46}$. No tiene fuentes (núm. 23).

- Aumenta la población, aunque su vivir es labrar el campo y criar ganado con pocas posibilidades (núms. 40 y 42).

- Tiene una iglesia dedicada a San Vicente, y una ermita de Sta. Crispina (núms. 48 y 52).

3.3.7. Fuenllana (Ms. J.I.14, ff. 302-305; Transc., pp. 259-263)

- Es pueblo antiguo (núm. 2). Situado en tierra alta, entre dos cerros, fría y rasa; no montuosa ni enferma (núm. 17). Abun-

$44 \quad$ Era la tercera parte de los diezmos eclesiásticos. Terzuela era la porción o cantidad que recibían los capitulares obligados a coro, en las iglesias que existe Cabildo, por la asistencia al Oficio de Tercia, anterior a la Misa Mayor o Conventual.

45 Un millón es igual a un cuento.

46 Medida de longitud que equivalía a 7 pies, y en superficie, $49 \mathrm{~m}$. cuadrados. 
dante en agua, con una fuente a las afueras que llaman del mármol, y da para todos (núm. 23).

- Posee vestigios de un castillo y restos de haber sido amurallada (núm. 36).

- La suerte de los edificios son de tierra y piedra, cal y yeso, madera y teja; los materiales los traen de fuera, aunque la tierra, el yeso y la cal se produce en el término. Las maderas vienen de las sierras de Alcaraz y Segura (núm. 35).

- Los vecinos son labradores y se está despoblando porque se van a vivir a Villanueva de los Infantes (núms. 39 y 40).

- A los Alcaldes ordinarios (dos) se les da de salario $500 \mathrm{mrs}$. al año, y 300 a los Regidores (dos); el escribano público del Concejo percibe $6000 \mathrm{mrs}$. al año, pero no cobra derechos ningunos (núm. 44).

- Tiene una iglesia bajo la advocación de Sta. Catalina, y cuatro ermitas próximas al pueblo: de San Salvador, la Concepción, San Benito y San Cristóbal (núm. 51).

3.3.8. Membrilla (Ms. J.I.14, ff. 275-282; Transc., pp. 303-312)

- Es una villa antigua, llamada originariamente Membrilla del Tocón, porque en sus proximidades existía un castillo levantado sobre un tocón (núm. 1).

- También sus redactores tratan de ubicarla detalladamente: pertenece al reino de Toledo, su asiento es la Mancha, y es el primer pueblo del partido del Campo de Montiel, viniendo de Toledo hacia Ruidera (núm. 4).

- Está en tierra llana, fría y rasa; lugar enfermo de piedra y piernas (núm. 17). Pobre de leña ya que tienen en poca cantidad, de jara, romero, retama y sarmientos (núm. 18).

- Tiene buenos pozos de agua dulce, junto al pueblo, y se vende a 2, 3 y 4 mrs. la carga de cuatro cántaros; agua salobre hay en todo el pueblo (núm. 23).

- El desarrollo de la población está estancado (núm. 39). Los vecinos son pobres y el principal oficio es labrar la tierra y criar ganado; hay cinco ó seis tiendas de mercería de poco caudal y algunos paños y sedas que se proveen de Toledo. Se hacen tinajas mejores que en otras partes y se labran algunos paños (vellorii) muy buenos (núm. 42).

- Tiene una iglesia bajo la advocación de Santiago, y en la villa y extramuros está la ermita de Ntra. Señora (en el castillo del Tocón) de enorme devoción en toda la comarca, con romería el primer domingo de Mayo. Se han experimentado 
muchas curaciones por los exvotos que se ven y otros llamativos portentos. A mitad de camino, entre la villa y Manzanares, está la ermita de Sta. Ana, donde se halló un importante tesoro consistente en una tinaja de 16 arrobas llena de planchas y ladrillos de oro, por el año 1505; la tinaja se conserva en el castillo de Manzanares (núm. 51).

\subsubsection{Montiel (Ms. J.I.14, ff. 262.273; Transc., pp. 339-352)}

- Es un pueblo noble y antiguo, tomado a los moros el día de todos los Santos de 1256 (núms. 2 y 3); es cabeza del territorio de su nombre, enclavado en el reino de Toledo (núm. 4).

- Esta villa, con el resto de pueblos del partido del Campo de Montiel, forman una Vicaría y juzgado eclesiástico, cuyo titular reside en Villanueva de los Infantes, y es fraile de la Orden de Santiago, como los demás clérigos del resto de los pueblos, por pertenecer a la dicha Orden (núm. 12).

- Está situado en lugar raso y sano, no tiene monte y es frío (núm. 17); es tierra fértil y tiene falta de leña, que se trae de dos leguas, principalmente sabinas y cepas (núm. 18). Se provee de agua de una fuente llamada Santa, a dos tiros de ballesta del pueblo y de la del Maguillo que, por medio de conduciones, llega hasta la plaza; algunos años pasan necesidad (núm. 23).

- Hay una casa que es lavadero de lanas, en donde ordinariamente se lavan unas 50.000 arrobas, propiedad de Genoveses, y esto ha provocado la destrucción de los montes y la grave necesidad de leña que padecen, haciendo, además, daño a las huertas (núm. 25).

- Tiene un castillo enclavado en un cerro alto y redondo; por descuido de sus Alcaides ha venido en quiebra; es de S.M., y desde hace treinta años no tiene Alcaide, que siempre lo fue el Comendador de la villa (núm. 33).

- Hay un solar de casa, junto a la plaza, con dos paredes viejas y una puerta con un escudo de la Orden de Santiago, en la que, según la tradición, murió el rey D. Pedro a manos de su hermano el Infante D. Enrique (núm. 36).

- Disminuye la población (núm. 39); tenía mercado franco los jueves, que ya no se guarda (núm. 46), y una feria por los Stos. Simón y Judas (núm. 56).

- Tiene una iglesia cuya renta asciende a 200 duc. anuales, y una ermita de Santiago, con un Cristo grande que, según los informantes, es cosa cierta que se apareció allí el año 1520; 
imagen enormemente milagrosa y de gran devoción. Hay otras dos ermitas: de Ntra. Sra. de los Mártires y Ntra. Señora de los Monasterios (núms. 50 y 51). Próxima a la barbacana del catillo había una cerca de piedra que llevaba a la iglesia vieja de Ntra. Sra. de la Estrella. Dentro del castillo existe una buena capilla con una imagen de alabastro del señor Santiago de la Espada (núm. 33).

- El pueblo está en el camino real de Valencia a Sevilla, y de la Tierra de Alcaraz y reino de Murcia al Campo de Calatrava y reino de Toledo (núm. 55).

- De las aldeas que un día tuvo bajo su jurisdicción, ahora sólo le quedan tres: Torres, Cañamares y Sta. Cruz de los Cáñamos (núm. 56).

3.3.10. Ossa de Montiel (Ms. J.I.14, ff. 357-364v; Transc., pp. 221-229).

- La villa es muy antigua (núm. 3); con todo detalle explican su vinculación y aseguran que cae en el reino de Castilla, en el Campo de Montiel, de la Orden de Santiago, y no está en frontera ninguna (núm. 4). Enclavada en una hondonada al pie de la Sierra de Alcaraz; es tierra fría, de grandes montes y muy enferma (núm. 17).

- Tiene abundancia de leña de encina, sabina y romero, para quemar en invierno; en los dichos montes se crían liebres, perdices, conejos, lobos y marotos (núm. 18). También es abundosa en agua, por estar próxima la ribera del río Guadiana; tiene muchas fuentes de donde se proveen la gente del campo y los ganados; en el pueblo hay una fuentemanantial y 3 ó 4 pozos dulces (núm. 23).

- Es muy pobre la cosecha de pan por ser las tierras ruines, y por esta causa los labradores que labran son pocos y les falta pan, que lo consiguen a seis leguas, a mucha costa, malo y caro. También es reducido el número de personas que tienen ganados. La cosecha de vino que se coge es pequeña por tener pocas viñas y malas. No tienen médico ni cirujano por ser pobres y no lo pueden sustentar; van por ellos a dos o tres leguas, y cuando vienen, el enfermo o enfermos, son muertos. Por esto el pueblo viene en disminución (núm. 26).

- Cuando la guerra de las Comunidades sufrieron una gran invasión de soldados (unos 1.400), los cuales echaron a perder a los vecinos y destruyeron las haciendas; quedó tan diezmada la villa que aún no se ha recuperado, sirviendo para 
agravar su pobreza. Los pueblos comarcanos no ayudaron porque este pueblo no quiere entrar en el Común de los demás del Campo de Montiel (núm. 37). El pueblo disminuye y se empobrece (núm. 39).

- Tiene una iglesia dedicada a Sta. María Magdalena, y una ermita próxima de Sta. Catalina; a una legua, otra de San Pedro de Sahelices, donde van en procesión el día de las Letanías Mayores (núm. 48 y 52).

- Celebra una gran feria por San Martín, que comienza en los Santos y llega hasta San Eugenio; en algunos casos, por mal recibimiento y trato a los vendedores forasteros han hecho que se marchen sin hacer tratos. Es camino pasajero de toda la Mancha. (núm. 55).

3.3.11. Puebla del Príncipe (Ms. J.I.14, ff. 505-507; Transc., pp. 401-404)

- Originariamente se llamó Puebla de Montiel, de cuya villa era aldea, hasta que el Príncipe D. Felipe la eximió e hizo villa, en ausencia del emperador, el 27-V-1553, y en su honor cambió de nombre (núms. 1, 2 y 26).

- Está situada en el reino de Toledo, en el Campo de Montiel, entre la Mancha y la Sierra de Segura, casi en las faldas de Sierra Morena (núm. 3).

- El pueblo y su término es tierra fría; al mediodía es tierra de monte; al oriente, cierzo y poniente, es tierra rasa, quebrada y sana (núm. 17). Abundante en leña de encina, romero, jara y roble; es zona de perdices y conejos (núm. 18).

- Es buena tierra de labranza (trigo, cebada y centeno); tiene algunas viñas y no hay ganados porque los vecinos son pobres para criarlos y sostener la cabaña (núms. 23 y 28).

- Las casas son ruines, de piedra y tierra, y cubiertas de teja y algunas de retama; malos edificios. Piedra y tierra hay en abundancia en la villa; la madera se suele traer de Segura y Alcaraz, y la teja de Almedina (núm. 25).

- La población disminuye por muertes y venir tiempos de necesidad, que han favorecido la emigración a otros lugares; también ocasionó el descenso la guerra de Granada, y a las Alpujarras y otros lugares de aquel reino se han ido avecindando muchos vecinos de aquí (núm. 26).

- Tiene una iglesia bajo la advocación de Sta. María, y dos ermitas, en su término: de Sta. María de Mairena y de San Matías (núm. 33). 
- La villa es pueblo muy pasajero por estar en el camino real de Valencia a Sevilla, y de la Mancha a Granada (núm. 36).

- Es un pueblo moderno, no ganado a los moros, que surgió alrededor de una torre, donde ahora está la iglesia, en la que se refugiaban los labradores que por allí tenían alguna labor (núm. 2).

- Está enclavada en el reino de Toledo, en la provincia, partido y vicaría del Campo de Montiel; pueblo de la Orden de Santiago, cuya gobernación está en Villanueva de los Infantes (núms. 4,10 y 12).

- El lugar donde está fundado es tierra fría, llana y rasa; tenida por sana de enfermedades, porque se crían niños sanos y recios (núm. 17).

- Veinticinco años antes que Cervantes lo inmortalizase, los redactores recogen la leyenda de Montesinos y su bella dama. A seis leguas está el nacimiento del Guadiana, en donde hay grandes piélagos de agua que dicen son las mayores lagunas de España. En la mitad de la más principal, hay un edificio arruinado que comúnmente llaman en esta tierra el castillo de Rochafrida, donde dicen que antiguamente vivió una hermosa doncella que se decía Rosa Florida; la pidieron en matrimonio Duques y Condes de Lombardía, y otras partes, y a todos despreció, porque se enamoró de las aventuras que le contaron de Montesinos. Mandólo a buscar y lo trajo y se casó con él y allí vivieron. Para llegar al castillo existe un puente de madera, porque, como dice el romance, por agua tiene la entrada, y por el agua la salida. Cerca está una cueva que llaman de Montesinos, por dentro de cual pasa el Guadiana, de cuya agua se abastecen los pastores que por allí andan (núm. 20).

- Es tierra de pan, y vino; los tintos son los mejores que se cogen en la comarca y otros lugares, siendo famosos en muchas partes del reino; en cambio, hay falta de frutas, legumbres y hortalizas, porque no hay huertas (núm. 26).

- Actualmente crece y se multiplica (núm. 39); la mayor parte de los vecinos viven de sus trabajos con necesidad, y hay algunos ricos, que no son muchos (núm. 42).

- Tiene una iglesia dedicada a Sta. Catalina, y dos buenas ermitas: de la Asunción y de San Sebastián (núms. 51 y 52). 
- Es lugar pasajero por estar en camino real de la Andalucía, a la salida del Puerto de Muladar de Sierra Morena, para pasar a la Mancha y pueblos del Marquesado de Villena (núm. 55).

3.3.13. Terrinches (Ms. J.I.14, ff. 379-391v; Transc., pp. 489-501)

- Es pueblo antiguo, ganado a los moros; pertenece a la Orden de Santiago, en el partido del Campo de Montiel y formando parte de la Encomienda Mayor de Castilla y del arcedianazgo de Alcaraz (núms. 1, 2 y 4).

- Tiene hecha comunidad con todas las villas del Campo de Montiel y se juntan en Montiel, cabeza del partido, dos personas por pueblo, elegidos por sus respectivos Concejos, para hacer los repartimientos y platicar lo que cada villa quiere; de lo acordado dan noticia a S.M., pidiendo su confirmación, que otorga el Real Consejo de Órdenes (núm. 8).

- La villa está enclavada en un valle y es sana; la parte superior, es tierra alta y fría; la baja, más cálida y no llana, porque tiene por contorno las Sierras de Alcaraz y Segura. No es Mancha, ni serranía, ni Sierra Morena; está entre medias, de tal forma, que esta villa está en un cónclave (núm. 17).

- Es abundosa en aguas. En la plaza hay dos grandes caños y jamás falta, además de otras fuentes a las afueras; la de la Torre tiene un agua especial para los enfermos (núm. 23).

- Es el pueblo del Campo de Montiel con mayor tasa de hidalgos, teniendo en cuenta la población; de un total de 150 vecinos, 40 son hidalgos (núm. 40).

- Todos los vecinos viven de labrar las tierras, que no son de mucho llevar, porque las más de ellas son delgadas y cansadas, y tienen poco término; tanto de pan, como de vino y ganados, se coge poco. Por cada fanega de trigo de sembradura se recogen cuatro o cinco de cosecha (núm. 26). Por la esterilidad y angostura del terreno, la población está estancada (núm. 39); los vecinos son pobres y menesterosos, no hay más de 3 ó 4 más ricos, careciendo el pueblo de frutos y granjerías (núm. 42).

- Tiene una iglesia bajo al advocación de Sto. Domingo, con un cura y dos capellanes, los cuales viven pobremente. Hay una ermita de Ntra. Sra. de Luciana, muy adornada, y en la que se han visto grandes portentos; se celebra una devota romería de los pueblos comarcanos en las Letanías de Mayo, y misa todos los sábados (núms. 49 y 51). 
3.3.14. Torre de Juan Abad (Ms. J.I.14, ff. 365-318; Transc., pp. 523-539).

- Originariamente llamada Villa de Santiago; en tiempos de moros se pasó a designar la Torre Abad por un alcalde de la fortaleza, conocido como Juan Abad (núm. 1).

- En las juntas del partido habla, se sienta y firma los acuerdos en tercer lugar, tras las villas de Montiel y Alhambra (núm. 8).

- Está situada en tierra bermeja y fría, en la que hiela tardío; es llana y algo montosa al poniente y mediodía, por la proximidad de Sierra Morena y Cabeza del Buey. Medianamente sana (núm. 17).

- Abundante en leña de carrasca, roble, jara y algunos fresnos y álamos; se crían venados, jabalíes, liebres, conejos, perdices, zorros, lobos, tejones, cabras monteses, corzos, perdices, gatos cervales y algunos osos (núm. 18).

- Dispone de fuentes con muy buena agua, proveniente de pozos dulces y salobres (núm. 23); se produce trigo, cebada, centeno y vino; se cría ganado vacuno, lanar, cabrío y puercos; tiene falta de una dehesa para el ganado, aceite, fruta y madera (núm. 26).

- En su término está enclavado el castillo de Montizón, que es casa y sitio fuerte, medianamente grande y con buenas dependencias; tiene alcaide que nombra el Comendador de Chiclana, a quien pertenece la fortaleza. Cobra anualmente de renta 24.000 mrs. en dinero y lo que puede labrar en la dehesa, además de tener allí veinte vacas y algunas yeguas (núm. 34).

- Por maltrato de los Señores Comendadores no se pobló como podría (núm. 37), y por quema de algunos herejes, disminuyó la población (núms. 36 y 39).

- Tiene una iglesia de cal y canto y mampostería, con cubierta de madera y teja, dedicada a Sta. María de los Olmos. Tiene dos ermitas: de San Pedro y de San Miguel; en el término está la ermita de Ntra. Sra. de la Vega para la que Jorge Manrique, Comendador de Montizón, hizo un retablo noble. Antiguamente hubo allí monasterio de frailes, y el día de la natividad de la Virgen se celebra una gran romería por la mucha devoción que se le tiene en la comarca (núms. 48 y 51).

- Es un pueblo con hidalgos - la mayor parte de ellos labradores- que gozan de no pechar ni contribuir en los servi- 
cios reales que se reparten a la villa y sus vecinos, salvo los que van a la iglesia, y los que se destinan a reparar puentes y fuentes; tampoco pagan moneda forera, ni les reparten huéspedes, y gozan de la mitad de los oficios reales (núm. 40).

- El pueblo está en el camino real de carros, y es lugar pasajero de Andalucía a la Corte, a la Mancha y a muchas partes; tiene en el término la venta del Villar, del Duque de Feria, Comendador de Segura (núm. 55).

\subsubsection{Torrenueva (Ms. J.I.14, ff. 308-312v; Transc., pp. 541-545)}

- Era una dehesa de la Encomienda Mayor de Castilla y se pobló por decisión del Capítulo de la Orden de Santiago celebrado en Uclés en 1440 (núm. 2).

- Es tierra fría, quebrada y rasa; lugar enfermo (núm. 17); tiene leña, pero no en abundancia. Se crían liebres y perdices, aunque no en mucha cantidad (núm. 18). Beben el agua de pozos, y no es buena (núm. 23).

- El trabajo de sus hombres es la labranza de cereales y la cría de ganado lanar, vacuno y cabrío. Como dato valioso aseguran que el trigo en años buenos vale a 6/7 rs. la fanega, y la cebada, a 7/7,5 rs; después de dezmados, los chotos suelen valer hasta 10 rs. la cabeza (núm. 32). La población es más grande que nunca (núm. 39).

- Tiene una iglesia bajo la advocación del señor Santiago, y cinco ermitas: de Santiago, San Juan, San Bartolomé, San Marcos y San Cristóbal (núms. 45 y 51).

- Celebran voto a Santiago por la peste; para la fiesta se reparte caridad, y para ello, cada vecino entrega un celemín de grano por caíz recogido ${ }^{47}$. Se solía dar una ración de carne y pan cocido; el día de Santiago se daba a todos los niños. Los vecinos que no sembraban pagaban un real; las viudas y los menores, medio real, aunque siembren, pero no llegando a un caíz su cosecha el día de San Pantaleón. Además, los días de San Pantaleón, todos los Santos y San Matías, hacen fiesta por voto, y solían dar una caridad de garbanzos y vino la víspera de cada fiesta. Por abusos cometidos, los Visitadores de Santiago, suprimieron las caridades el año anterior de 1574, ordenando que sólo se diese a los niños el día

47 Medida de capacidad que equivalía a 12 fanegas. 
de Santiago que celebran en su ermita el primer domingo de mayo (núm. 52).

3.3.16. Villahermosa (Ms. J.I.14, ff. 292-298; Transc., pp. 563-570)

- Es pueblo nuevo y nunca fue de moros; anteriormente se llamaba Pozuelo, cuando era aldea, por un pozo que está a orilla del pueblo, hacia el cierzo; el Infante D. Enrique de Aragón al emanciparla de Montiel y hacerla villa, el 22-IX1444 , le dió el actual nombre (núms. 1 y 2).

- Aunque es tierra alta, está asentada en una hondonada; es fría y muy húmeda. El agua de los pozos es muy somera, y en años lluviosos se hacen fuentes en las propias casas, originándose epidemias de tercianas y cuartanas (núm. 17).

- En las riberas del río Jabalón, que pasa junto a Montiel, tienen huertas donde se recogen legumbres; es ribera de labor muy buena, y ahí siegan los panes en tiempos de necesidad. En los márgenes del Azuer se crían buenos membrillos y cáñamos, y hay buenas arboledas. Es tierra de mediana labor (núm. 21). El trigo que se coge es muy bueno y responde muy bien para pan cocido; tiene una cabaña de 30.000 cabezas, aprox. de ganado lanar y cabrío (núm. 26).

- La población ha ido siempre en aumento; la mayor parte de la gente es rica y hay pocos pobres, porque todos trabajan; se labra la tierra lo mejor que se conoce en la redonda (núms. 39 y 42).

- Tiene una iglesia dedicada a Sta. María y tres ermitas: de San Pedro, San Sebastián y San Agustín; además hay un Humilladero y un Calvario (núms. 48 y 51).

- Cosa digna de tener en cuenta es que los informantes aseguran que existe un buen orden y armonía entre los vecinos, y que casi ninguno, en días de trabajo, dejan de faenar, de tal forma, que en los días laborables hay poca gente con quien conversar. Por eso en esta villa se vive con más bienes temporales que en otras. Igualmente las mujeres trabajan afanosamente y destacan por su honestidad. Tienen a gala no casarse con gente de origen de moros o judíos; por eso no hay sambenitos ni penitenciados por la Inquisición. Son muy formales en sus contratos y actúan sin hipocresía ni vanos cumplimientos (núm. 57).

- Es pueblo pasajero de Cuenca a Granada, y de Valencia al Campo de Calatrava (núm. 55). 
3.3.17. Villamanrique (Ms. J.I.13, ff. 65-70v; Transc., pp. 571-574)

- Antes se llamaba Balmontejo de la Sierra, y al hacerla villa el Maestre de Santiago, D. Rodrígo Manrique, el 18-XII-1474, tomó el nombre actual (núms. 1 y 2).

- Es tierra fría, quebrada y seca; está al pié de Sierra Morena, al mediodía; es montuosoa y áspera, pero sana (núm. 17). Tiene leña abundante: jara, romero y algunas encinas y maraña; hay mucha caza de perdices, algunos venados y jabalíes. No tiene término (núm. 18).

- El río Guadalmena, que pasa a dos leguas, suele tener muchas crecidas, arrastrando bastantes árboles y destrozando los puentes de cal y canto; por ser necesario cruzarlo personas, cabalgaduras y ganados, se construyó un puente principal, a costa de los pueblos del partido del Campo de Montiel y villa de Segura, en poco menos de tres años, que ha costado 14.000 duc., a pesar de tener los materiales al pié del lugar; es una obra excelente y de grande aprovechamiento (núm. 22).

- La gentes es más pobre que rica y su trato es labrar la tierra y criar ganado (núm. 42).

- Tiene una iglesia cuyo titular es San Andrés, y un voto el día de la Magdalena, por la peste, en el que se matan dos vacas y se dan de caridad a los vecinos (núms. 49 y 52).

- Es lugar muy pasajero del reino de Valencia al de Granada y Andalucía, de la Mancha y Priorato de San Juan para Granada y la Corte y reino de Toledo y Campo de Calatrava (núm. 55).

3.3.18. Villanueva de los Infantes (Ms. J.I.14, ff. 383-344; Transc., pp. 585-592).

- Es población nueva. Originariamente se llamó la Moraleja cuando era aldea de Montiel; poco después de hacerla villa el Infante D. Enrique de Aragón, se comenzó a llamar así, siendo ratificado en el Capítulo que la Oden de Santiago celebró en Uclés el 1480. Junto al río Jabalón, a una legua pequeña del pueblo actual, hubo anteriormente población, en un lugar llamado Jamila; por ser lugar húmedo y enfermo, los moradores se trasladaron a este enclave, con el nombre anterior de Moraleja; este cambio ocurría por 1415, según los documentos que afirman tener (núm. 2). 
- Cae en el reino de Toledo, en los principios de Sierra Morena, en el Campo de Montiel, que es entre la Mancha y Sierra Morena; pertenece al priorato de Uclés de la provincia de Castilla (núms. 4 y 12).

- Es cabeza de la Gobernación del Campo de Montiel; aquí reside la Justicia Mayor, y es adonde vienen en grado de apelación todas las demás villas y conoce de todos los casos criminales. También es donde se cobran las alcabalas y servicios, subsidios y escusados de este partido y de los de Segura de la Sierra y Caravaca. Es Vicaría del partido y aquí reside su titular con los miembros de su audiencia (núms. 10 y 12).

- La tierra es más buena que mala; es tierra para pan, vino tinto y ganados. Por estar en alto la tocan todos los vientos; en invierno es fría, y caliente en verano, por la reverberación del sol. No es serranía, ni muy llana; tierra rasa, sin monte ni árboles. Aunque es tierra natural de monte, que en todas partes lo hay y nace, lo rozan y los ganados lo gastan. Se tiene por tierra sana y se ve que lo es, porque hay viejos y pocos enfermos (núm. 17).

- En las riberas del Jabalón hay una buena huerta de membrillares, aunque algunos años se hielan, y por no aplicarse la gente de la tierra, no hay buenas huertas y arboledas de frutales en las dichas riberas y otras vegas, que las hay muy buenas, y con agua, lo que sería de mucho aprovechamiento; las huertas de la villa se riegan con agua de norias. No hay arboledas en las huertas y en la villa, porque no se dan a ello, antes, cortan los árboles que hay porque son poco inclinados a ello (núm. 21).

- Las casas son comúnmente de tapias de tierra; casas bajas por la mayor parte, sin ventanas ni luceros a las calles; hay en la tierra, piedra, cal y yeso, pero no madera; por ser la mayoría de los vecinos labradores, las habitaciones son abajo y las cámaras en lo alto, para el trigo. La cobertura es de teja, y se hace aquí. En el momento presente se comienzan a labrar algunos altos y haciendo ventanas (núm. 35).

- La población es grande, la mayor del Campo de Montiel, con 1.300 vecinos. Tiene una fuerte población morisca que alcanza el 23\% del total (1000 cristianos viejos y 300 moriscos (=6.500 habitantes, aprox.). Siempre ha ido en aumento y está creciendo ${ }^{48}$ (núm. 39).

48 Para ver su trayectoria indicamos el número de nacimientos, tomado por los libros parroquiales, en el período 1575-1600; total de bautismos celebrados (na- 
- La iglesia es un buen edificio de una nave; tiene una torre muy buena, alta y muy galana, labrada de sillería, con ventanas y chapitel de pizarra negra y plomo, como las que el rey ha mandado hacer en El Escorial. Está dedicada a San Andrés, y luego tiene una ermita de San Cristóbal. Dan de limosna a los pobres, por voto a San Agustín, lo que se daba antes en caridad (núms. 36, 38 y 52).

- Generalmente la gente de esta villa tiene de comer y de qué sustentarse; hay muy pocos pobres naturales. Tiene entre ricos y no ricos una medianía que antes se llega a llamar ricos que pobres; las granjerías son de pan, vino y ganados de los más comunes, aunque hay personas que viven de tratos y compraventa de cosas (núm. 42).

- Tiene un Monasterio de franciscanos para el que dio licencia el Maestre de Santiago, en 1483, con 40 frailes, y otro de monjas franciscanas - originariamente beaterio-dedicado a la Inmaculada Concepción, que se ha erigido canónicamente el día de San Agustín de este año 1575, con 200 ducados de renta y 35 religiosas (núm. 53).

- Existen tres hospitales; dos son casas de fundación privada, para pobres del pueblo, y uno del Concejo, para enfermos. El Hospital de Santiago lo fundó Juan Pérez Cañuto; el otro, D. ${ }^{a}$ Lucía [Martínez] Castellanos, madre de D. fray [Santo] Tomás de Villanueva; ambos con algo de renta. El del Concejo, sin renta, se sostiene de limosnas particulares (núm. 54).

\section{CONCLUSIÓN}

Por mantener la estructura general en este tipo de estudios incluimos este apartado, aunque poco podemos decir después de lo que queda escrito. Hemos escuchado lo que los redactores de las villas contestaron de sus respectivos pueblos. Retrato fiel de una realidad viva, tomada a fines de 1575 . Relato testimonial y narración suficientemente detallada para hacernos idea exacta de cómo eran los lugares el Campo de Montiel.

cimientos): 4.914. En esa cifra hay las siguientes peculiaridades: Hijos naturales, 39; Niños abandonados al nacer, 81; Hijos de cristianos nuevos, 175; Hijos de esclavos, 8. A partir de 1610, fecha de la expulsión de los Moriscos, no existen bautismos de ningún niño, hijo de cristiano nuevo del antiguo reino de Granada. CAMPOS, F. J., «Demografía Manchega. Aproximación a la historia de Villanueva de los Infantes a través del estudio de su archivo eclesiástico», en Anuario del Real Colegio de Alfonso XII (San Lorenzo del Escorial), 1 (1983) sin paginar. 
Con estas descripciones en la mente podemos ahora tomar el Quijote y comprobaremos que en sus páginas se reflejan tipos y lugares, costumbres y paisajes, más arriba apuntados. Cervantes no tuvo que forzar la imaginación para crear una realidad, sino trasladar al papel lo que veía, que no era distinto de lo que pocos años antes habían dicho unos hombres buenos y entendidos de estos pueblos, en las respuestas al cuestionario real, conocido hoy como las Relaciones Topográficas.

Hay unos hechos comúnmente repetidos en las descripciones de los pueblos que confirman la evidencia de los hechos. Los redactores fueron testigos fieles, escribanos de la experiencia, cuyo testimonio luego ratificaron los respectivos escribanos públicos y de los Concejos, al legalizar sus declaraciones.

Según esas informaciones, podemos afirmar:

1. Existe un clamor generalizado, con acentos dramáticos, por la pobreza en que viven: malas cosechas, pequeñez de los términos, baja calidad de la tierra, dureza del clima...

2. Es una tierra cuya economía está centrada exclusivamente en el sector primario, con pequeñas explotaciones agropecuarias, que en la mayoría de los casos, rentan lo mínimo y menos, no siendo raro que tengan que salir a trabajar en campos de otros términos municipales, incluso emigrar.

3. Tienen carencia de algunos productos necesarios: aceite, frutas, hortalizas, mercaderías, madera...

4. En la mayoría de los pueblos disponen de suficiente agua, que juzgan de buena calidad, y de caza, por la proximidad a Sierra Morena. Es llamativo, sin embrago, que en ningún caso se quejen de daños causados a la agricultura o las viñas, por la caza.

5. Poseen malas viviendas, por falta de materiales, deficiencia de los mismos, carencia de algunos y carestía.

6. La escasez de medios económicos y la pobreza de recursos, hace que en algunas villas esté dísminuyendo la población (en seis), y en otros casos esté estancada (en cuatro). Existe crecimiento de vecindario en siete pueblos, pero se debe mayoritariamente a una emigración interna, con familias que proceden de otros pueblos del mismo partido.

7. En la mayoría de las Relaciones aseguran que hay población de cristianos nuevos, es decir, moriscos provenientes del antiguo reino de Granada, dispersados por tierras de la Mancha tras la guerra de las Alpujarras -años 1570/71 - hasta el decreto de expulsión de la Mancha, el 10 de Julio de 1610.

8. Tratándose de un territorio perteneciente a la jurisdicción de la Orden de Santiago, y con clero mayoritariamente de ella, sorpren- 
de que la devoción al Padre y Patrón de la institución no haya calado fuertemente en el territorio y sus gentes, ya que es reducido el número de las parroquias dedicadas a la advocación de Santiago (sólo tres), ni sea abundante las ermitas levantadas al apóstol (sólo cinco).

9. Todas las villas, menos dos, afirman que tienen hidalgos, en todas sus modalidades: de sangre y de privilegio, viejos y nuevos; en algunos pueblos aseguran que, en esos momentos, pleitean las ejecutorias de sus hidalguías en la Chancillería de Granada especificando incluso los privilegios que goza este grupo social.

10. Si es cierto que D. Quijote comenzó su andadura partiendo del Campo de Montiel, y tan bien reflejados quedan los pueblos de esta comarca en la obra cervantina, ratificado por las Relaciones Topográficas, no sería descabellado pensar que quizás alguno de los hidalgos de estas villas fuese Alonso Quijano el Bueno, que Miguel de Cervantes supo transformar en Don Quijote de la Mancha, haciéndonos en él grandes a todos los hombres del Campo de Montiel.

\section{APÉNDICES ${ }^{49}$}

\subsection{Vecindario y grupos}

\begin{tabular}{|c|c|c|c|c|}
\hline Poblaciones & $\begin{array}{l}\text { Núm. total } \\
\text { vecinos }\end{array}$ & $\begin{array}{l}\text { Vecinos } \\
\text { hidalgos }\end{array}$ & $\begin{array}{l}\text { Vecinos } \\
\text { moriscos }\end{array}$ & $\begin{array}{l}\text { Evolución } \\
\text { población }\end{array}$ \\
\hline Albaladejo & 300 & No & $\mathrm{Si}$ & + \\
\hline Alcubillas ........................................ & 130 & 3 & $\mathrm{Si}$ & $=$ \\
\hline 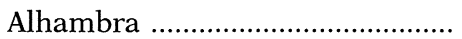 & 200 & 8 & 10 & - \\
\hline 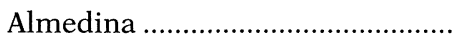 & 400 & 12 & ? & $=$ \\
\hline Cañamares ...................................... & 20 & ? & ? & ? \\
\hline 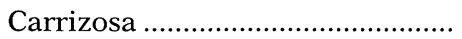 & ? & ? & ? & ? \\
\hline
\end{tabular}

49 Los datos están tomados de Campos, F. L., La Mentalidad, o. c., pp. 154-199.

50 Somos conscientes de la dificultad existente a la hora de hacer la equivalencia entre vecino y habitante; en principio, vecino es toda persona independiente $\mathrm{y}$ con domicilio, sin mirar si tiene o no familia; es decir, un cabeza de familia, pero con complicaciones, porque en ese concepto se incluyen las viudas, los célibes, los clérigos, etc. Los demógrafos no se ponen de acuerdo a la hora de asignar un coeficiente para hacer la averiguación, entre otras cosas, por falta de uniformidad incluso dentro de la Corona de Castilla. Así nos encontramos desde un coeficiente 6 (Ruiz Almansa); 5 (T. González, Madoz), 4,5 (Castillo Pintado); 4 (G. Anes); 3,5 (López Salazar), etc. Con carácter meramente aproximativo podemos situarnos nosotros en el coeficiente 5 habitantes por vecino. Cfr. LóPEz SALAzAR, J., Estructuras agrarias y sociedad rural en La Mancha (siglos XVI-XVII). Ciudad Real 1986, pp. 57-85 y 672; CAMAcho Cabello, J., La población de Castilla-La Mancha (siglos XVI-XVIII). Ciudad Real 1997, pp. 22-23 y 81-85, especialmente. 
FRANCISCO JAVIER CAMPOS Y FERNÁNDEZ DE SEVILLA

\begin{tabular}{|c|c|c|c|c|}
\hline Poblaciones & $\begin{array}{l}\text { Núm. total } \\
\text { vecinos }\end{array}$ & $\begin{array}{l}\text { Vecinos } \\
\text { hidalgos }\end{array}$ & $\begin{array}{c}\text { Vecinos } \\
\text { moriscos }\end{array}$ & $\begin{array}{l}\text { Evolución } \\
\text { población }\end{array}$ \\
\hline Castellar de Santiago ...................... & 370 & 30 & ? & + \\
\hline 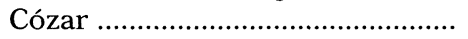 & 350 & 15 & ? & + \\
\hline 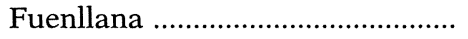 & 160 & 4 & ? & - \\
\hline 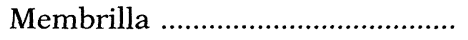 & 1.200 & 17 & 200 & $=$ \\
\hline 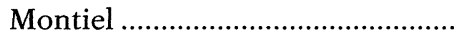 & 300 & 15 & ? & - \\
\hline 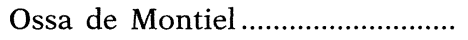 & 110 & 1 & ? & - \\
\hline Santa Cruz de los Cáñamos ...... & 25 & ? & ? & $?$ \\
\hline Puebla del Príncipe ..................... & 85 & 4 & ? & - \\
\hline 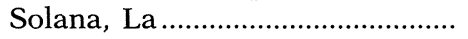 & 700 & 4 & 4 & + \\
\hline Terrinches ....................................... & 150 & 40 & ? & $=$ \\
\hline Torre de Juan Abad .................... & 300 & 11 & ? & - \\
\hline Torrenueva ................................... & 507 & 5 & 59 & + \\
\hline 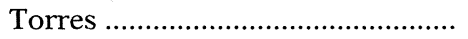 & 30 & ? & ? & ? \\
\hline Villahermosa ............................... & 500 & 12 & ? & + \\
\hline 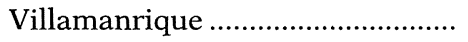 & 400 & 20 & 30 & $?$ \\
\hline Villanueva de los Infantes .......... & 1.300 & 40 & 300 & + \\
\hline Total (22 pueblos) .......... & 7.567 & 241 & 603 & \\
\hline
\end{tabular}

\subsection{Iglesia y ermitas}

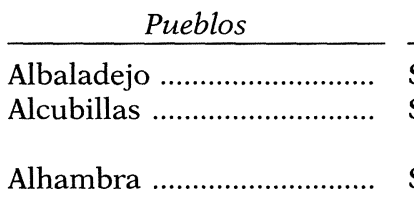

Almedina

Cañamares

Carrizosa

Castellar de Santiago

Cózar

Fuenllana

Membrilla

Montiel

Parroquia
Santiago
Sta. M. $^{\text {a Magdalena }}$

S. Bartolomé

Ntra. Señora

Ntra. Sra. Mártires ?

Sta. Ana

S. Vicente

Sta. Catalina

Santiago

Ntra. Sra. de la Es- 4: Santiago (2), Ntra. Sra. de los trella (vieja)

Ossa de Montiel

Puebla del Príncipe

Sta. M. ${ }^{a}$ Magdalena

Sta. María

Sta. Cruz de los Cáñamos . S. Bartolomé
Ermitas y advocaciones

2: S. Juan y S. Sebastián

3: Ntra. Sra. de la Carrasca, S. Ildefonso, S. Sebastián

6: S. Benito, Sta. Catalina, Sta. María de las Flores, Ntra. Sra. de la Carrasca, Ntra. Sra. la Blanca

5: Sta. María Magdalena, S. Nicasio, S. Cristóbal, Sta. Quiteria, S. Sebastián

No tiene

1: Sta. Crispina

4: S. Salvador, Inmaculada, S. Sebastián, S. Cristóbal.

3: Ntra. Sra., Sta. Ana, Santiago Viejo

Mártires, Ntra. Sra. de los Monasterios

2: Sta. Catalina, S. Pedro

2: Sta. M. ${ }^{a}$ Magdalena, S. Matías 


\begin{tabular}{|c|c|c|}
\hline Pueblos & Parroquia & Ermitas y advocaciones \\
\hline Solana, La ....... & Sta. Catalina & $\begin{array}{l}\text { 4: Asunción, S. Sebastián, S. } \\
\text { Antón, Sta. Elena }\end{array}$ \\
\hline Terrinches . & Sto. Domingo & 1: Ntra. Sra. de Luciana \\
\hline Torre de Juan Abad .............. & Sta. María de Olmos & $\begin{array}{l}\text { 6: Ntra. Sra. de la Vega, S. Pedro, } \\
\text { S. Miguel, Santiago, Sta. Bár- } \\
\text { bara, Capilla castillo de Mon- } \\
\text { tizón }\end{array}$ \\
\hline 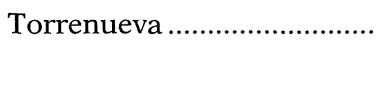 & Sta. María & $\begin{array}{l}\text { 5: Santiago, S. Juan, S. Bar- } \\
\text { tolomé, S. Cristóbal, S. Mar- } \\
\text { cos }\end{array}$ \\
\hline 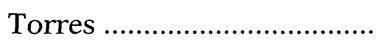 & ? & 1: S. Blas \\
\hline Villahermosa ............................. & Sta. María & $\begin{array}{l}\text { 5: S. Pedro, S. Sebastián, S. } \\
\text { Agustín, Un Calvario, Un Hu- } \\
\text { milladero }\end{array}$ \\
\hline 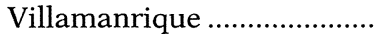 & S. Andrés & ? \\
\hline Villanueva de los Infantes.. & S. Andrés & 1: S. Cristóbal \\
\hline
\end{tabular}

\subsection{Fiestas y votos}

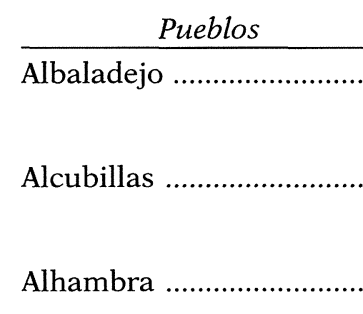

\section{Santos} S. Sebastián Conv. S. Pablo Sta. Quiteria Inmaculada Cruz de Mayo S. Juan ante P.L. S. Antón

S. Sebastián Sta. Águeda Cátedra S. Pedro S. Benito (2 días) Cruz de Mayo S. Vivar Sta. Catalina

Almedina

S. Nicasio

S. Sebastián

Sta. Catalina

Castellar de Santiago

S. Sebastián

S. Benito

S. Agustín

Cózar

S. Vicente

S. Crispín

Fuenllana Inmaculada

Membrilla Cruz de Mayo

Montiel S. Agustín Víspera Corpus

S. Sebastián

S. Miguel Mayo

\begin{tabular}{|c|c|}
\hline Motivo & Prácticas \\
\hline Varios & Abstinencia \\
\hline Varios & Abstinencia \\
\hline Varios & Abstinencia \\
\hline Langosta & Procesión \\
\hline$?$ & Procesión \\
\hline ? & Procesión \\
\hline Devoción & $?$ \\
\hline Voto & ? \\
\hline Piedra & Ayuno y Abst. \\
\hline Langosta & Ayuno y Abst. \\
\hline Devoción & ? \\
\hline Agua & Proces. y Abst. \\
\hline Hielo & Caridad y Abst. \\
\hline Devoción & ? \\
\hline Peste & ? \\
\hline ? & ? \\
\hline Langosta & $?$ \\
\hline Devoción & ? \\
\hline Reliquia & ? \\
\hline Langosta & ? \\
\hline Advoc. Iglesia & ? \\
\hline ? & ? \\
\hline Langosta & Abstinencia \\
\hline Sequía & Abstinencia \\
\hline Hielo & $?$ \\
\hline Langosta & $?$ \\
\hline Langosta & Ayuno \\
\hline Peste & Ayuno \\
\hline Peste & Abstinencia \\
\hline
\end{tabular}




\begin{tabular}{|c|c|c|c|}
\hline Pueblos & Santos & Motivo & Prácticas \\
\hline 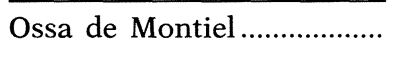 & $\begin{array}{l}\text { Letanías Mayores } \\
\text { S. Matías }\end{array}$ & $\begin{array}{l}\text { Peste } \\
?\end{array}$ & $\begin{array}{l}\text { Proces. y Abst. } \\
\text { ? }\end{array}$ \\
\hline Puebla del Príncipe ................ & Conv. S. Pablo & Peste & $?$ \\
\hline \multirow[t]{8}{*}{ 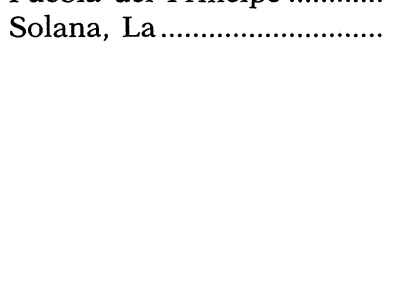 } & S. Juan Evangel. & Hielo verano & Vísperas y Misa \\
\hline & S. Agustín & Langosta & Caridad \\
\hline & S. Cosme y Damián & Gusano & ? \\
\hline & Fin Pascua Resur. & ? & Proc. y Caridad \\
\hline & Cruz de Mayo & Peste & Procesión \\
\hline & Sta. Catalina & Advoc. Iglesia & ? \\
\hline & S. Sebastián & $?$ & $?$ \\
\hline & S. Antón & ? & ? \\
\hline \multirow[t]{3}{*}{ 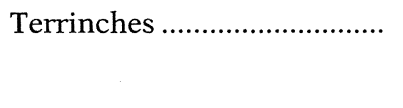 } & Sto. Domingo & Advoc. Iglesia & $?$ \\
\hline & S.Eugenio (tras.) & $?$ & ? \\
\hline & S. Esteban & Peste & Caridad \\
\hline \multirow[t]{3}{*}{ Torre de Juan Abad ................ } & Cruz de Mayo & $\begin{array}{l}\text { Frutos tierra y } \\
\text { salud pueblo }\end{array}$ & $\begin{array}{l}\text { Caridad, Proc., } \\
\text { Abst., Misa y } \\
\text { Vísperas }\end{array}$ \\
\hline & S. Nicasio & Ídem & Ídem \\
\hline & Sta. Bárbara & Ídem & Ídem \\
\hline \multirow[t]{7}{*}{ 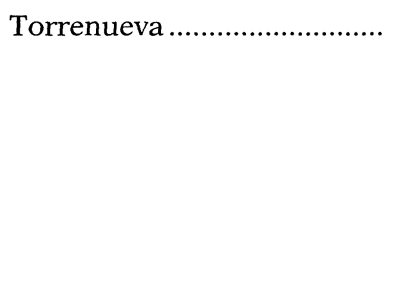 } & Santiago & Peste & Caridad \\
\hline & S. Pantaleón & ? & Caridad \\
\hline & S. Agustín & ? & Caridad \\
\hline & Todos los Santos & ? & Caridad \\
\hline & S. Sebastián & Peste & ? \\
\hline & 1. ${ }^{\circ}$ de Mayo & ? & $\begin{array}{l}\text { Procesión, Misa } \\
\text { y Caridad }\end{array}$ \\
\hline & Fin Pascua Resur. & ? & Procesión \\
\hline \multirow[t]{4}{*}{ 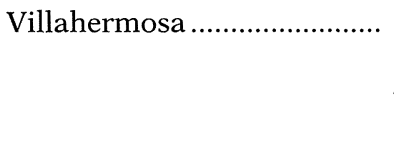 } & Conv. S. Pablo & Peste & Ayuno y Abst. \\
\hline & S. Sebastián & Peste & ? \\
\hline & S. Agustín & Langosta & Abstinencia \\
\hline & Martes Letanías M. & $?$ & ? \\
\hline \multirow[t]{2}{*}{ 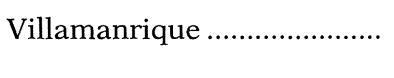 } & S. Pedro y Pablo & Langosta & ? \\
\hline & Sta. M. ${ }^{a}$ Magdalena & Peste & Caridad \\
\hline \multirow[t]{2}{*}{ Villanueva de los Infantes... } & S. Simón y Judas & $?$ & Caridad \\
\hline & Agustín & ? & Proc. y Caridad \\
\hline
\end{tabular}

\subsection{Hospitales}

$\frac{\text { Pueblos }}{\text { Albaladejo } . . . \ldots \ldots \ldots \ldots \ldots \ldots \ldots \ldots \ldots \ldots \ldots \ldots \ldots \ldots \ldots}$

\begin{tabular}{c} 
Núm. \\
\hline 1 \\
1 \\
1 \\
1 \\
1 \\
1 \\
1 \\
3
\end{tabular}

\begin{tabular}{lll} 
Fundación & & \multicolumn{2}{c}{ Renta } \\
\cline { 1 - 1 } Particular & & No \\
Particular & & No \\
? & & No. Limosnas \\
Particular & & No \\
Particular & & No. Limosnas \\
Concejo & & No \\
$?$ & & No. Limosnas \\
$?$ & & Sí \\
Particular & & No \\
Particular & & Sí
\end{tabular}




\begin{tabular}{|c|c|c|c|}
\hline Pueblos & Núm. & Fundación & Renta \\
\hline Montiel. & 1 & ? & No \\
\hline Ossa de Montiel .......................... & 1 & Concejo & No. Limosnas \\
\hline Puebla del Príncipe .................... & 1 & $?$ & No \\
\hline \multirow[t]{3}{*}{ 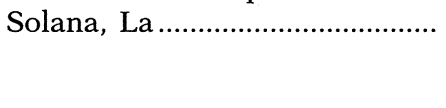 } & 3 & Particular & Sí \\
\hline & & Particular & No \\
\hline & $\cdot$ & $?$ & No \\
\hline Terrinches ................................ & 1 & ? & No \\
\hline Torre de Juan Abad .................. & 1 & Particular & Sí \\
\hline Torrenueva ............................... & 1 & Concejo & No \\
\hline Villahermosa ............................. & 1 & $?$ & Sí \\
\hline Villamanrique ........................... & 1 & ? & Sí. «San Pedro» \\
\hline \multirow[t]{3}{*}{ Villanueva de los Infantes ......... } & 3 & Concejo & No \\
\hline & & Particular & No. «Santiago» \\
\hline & & Particular & Sí \\
\hline
\end{tabular}

\subsection{Diezmos $^{51}$}

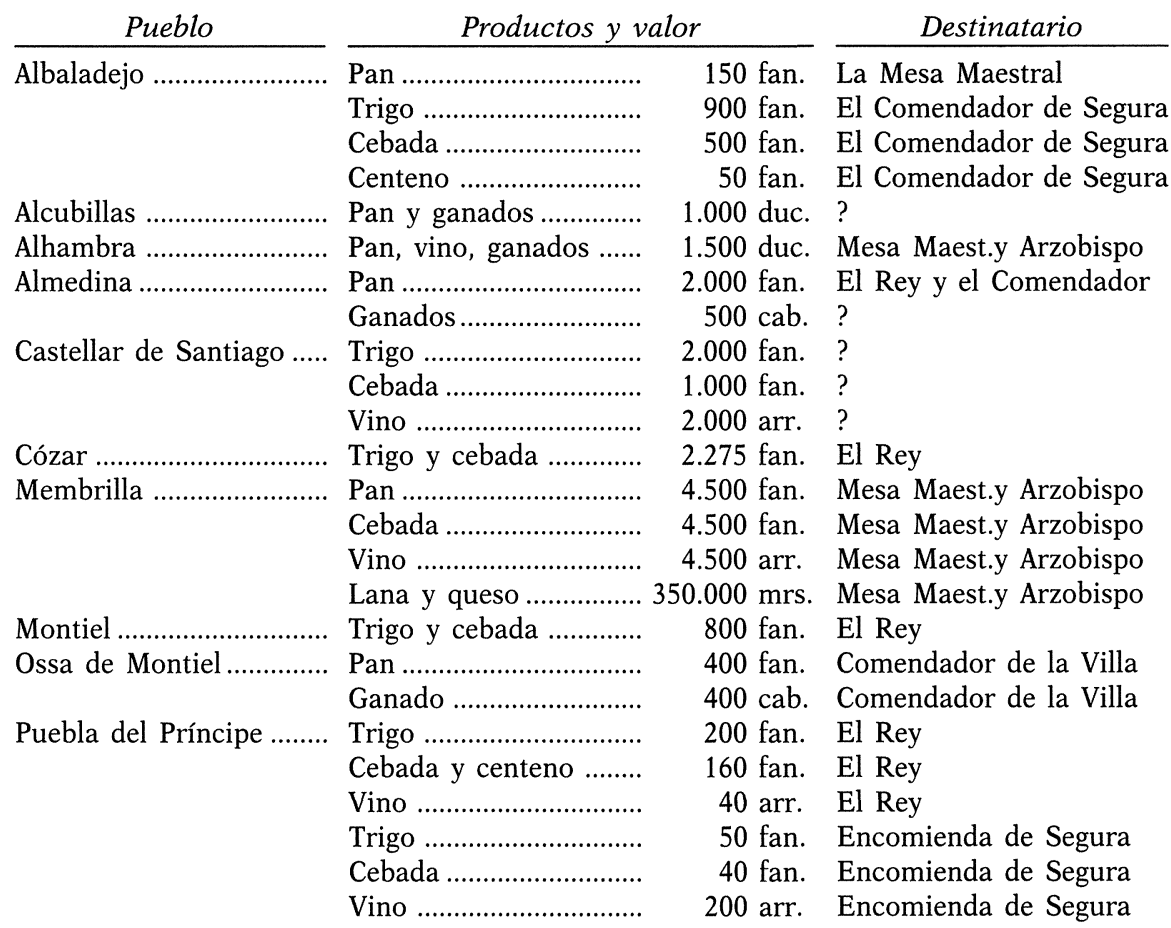

51 Por las cantidades dezmadas se puede conocer el volumen total de la producción, siempre con carácter aproximativo, teniendo en cuenta las lagunas e imprecisiones. 


\begin{tabular}{|c|c|c|c|}
\hline Pueblo & Productos y vo & alor & Destinatario \\
\hline Solana, La . & Pan ...... & 7.000 fan. & Encom., Arzob., Mesa M. \\
\hline & 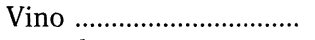 & 5.000 arr. & Encom. Villa y Arzob. \\
\hline & 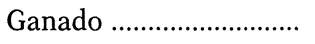 & $1.500 \mathrm{cab}$. & Encom Villa y Arzob. \\
\hline Terrinches ............................. & $?$ & ? & $\begin{array}{l}\text { Comend M Castilla, Arzob. } \\
\text { y Cvto. Uclés. }\end{array}$ \\
\hline Torre de Juan Abad & Pan . & 3.000 fan. & ? \\
\hline & Ganados y $\mathrm{r}$ & $140.000 \mathrm{mrs}$. & ? \\
\hline Torrenueva ........................... & Trigo ……....................... & 2.000 fan. & Encomienda M Castilla \\
\hline & Cebada ....... & 700 fan. & Encomienda M Castilla \\
\hline & 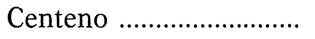 & 25 fan. & Encomienda M Castilla \\
\hline & Ganado ............................ & 900 cab. & Encomienda M Castilla \\
\hline Villahermosa ...... & Pan & 3.500 fan. & Comendador y Arzobispo \\
\hline & 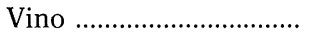 & 2.000 arr. & Comendador y Arzobispo \\
\hline & Ganado ........................... & $1.500 \mathrm{cab}$. & Comendador y Arzobispo \\
\hline & 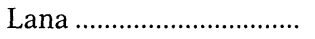 & 300 arr. & Comendador y Arzobispo \\
\hline & Menudos ....................... & 30.000 mrs. & Comendador y Arzobispo \\
\hline Villamanrique... & 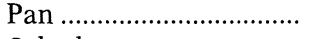 & 1.200 fan. & $?$ \\
\hline & Cebada ............................... & 600 fan. & ? \\
\hline & 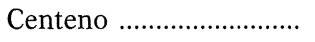 & 50 fan. & ? \\
\hline & Vino ........................ & 500 arr. & ? \\
\hline Vva. de los Infantes ........ & Trigo y cebada .............. & 800 fan. & ? \\
\hline & 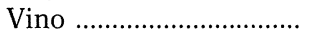 & 11.000 arr. & ? \\
\hline & Corder. y cabras ........... & $5.500 \mathrm{cab}$ & $?$ \\
\hline & Ganado, resto ................ & $232 \mathrm{cab}$. & ? \\
\hline & Lana .................................... & 500 arr. & ? \\
\hline
\end{tabular}

\subsection{Caminos y comunicaciones}

\begin{tabular}{|c|c|c|}
\hline Pueblos & Pasajero & Direcciones \\
\hline Albaladejo ......................... & No & $\begin{array}{l}\text { Cerca camino de Andalucía, La Mancha y } \\
\text { Valencia }\end{array}$ \\
\hline Alcubillas ............................ & Sí & Sevilla, Toledo y Madrid \\
\hline Alhambra ............................ & No & $\begin{array}{l}\text { Cerca camino de Vva de los Infantes y Gra- } \\
\text { nada }\end{array}$ \\
\hline Almedina & ? & No responde \\
\hline Castellar de Santiago ....... & ? & No responde \\
\hline 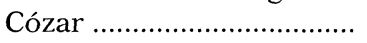 & $?$ & No responde \\
\hline Membrilla ............................ & $?$ & No responde \\
\hline Montiel ................................. & Sí & $\begin{array}{l}\text { Camino real de Valencia, Andalucía, Tierra } \\
\text { de Alcaraz, Murcia, Campo de Calatrava y } \\
\text { Toledo }\end{array}$ \\
\hline Ossa de Montiel... & Sí & La Mancha, sur del Tajo y Granada \\
\hline Puebla del Príncipe .......... & Sí & $\begin{array}{l}\text { Camino real de Valencia, Sevilla, La Man- } \\
\text { cha y Granada }\end{array}$ \\
\hline 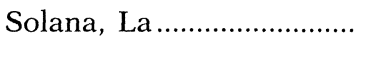 & Sí & $\begin{array}{l}\text { Camino real de Andalucía, Sierra Morena, } \\
\text { La Mancha y Marquesado de Villena }\end{array}$ \\
\hline Terrinches .. & No & \\
\hline
\end{tabular}




\begin{tabular}{|c|c|c|}
\hline Pueblos & Pasajero & Direcciones \\
\hline Torre de Juan Abad ......... & Sí & $\begin{array}{l}\text { Camino real de Andalucía, la Corte, la Man- } \\
\text { cha y muchos lugares }\end{array}$ \\
\hline Torrenueva ......... & No & \\
\hline Villahermosa..... & Sí & $\begin{array}{l}\text { De Cuenca, Granada, Valencia y Campo } \\
\text { Calatrava }\end{array}$ \\
\hline Villamanrique ................... & Sí & $\begin{array}{l}\text { De Valencia, Granada, Andalucía, La Man- } \\
\text { cha, Priorato de S. Juan, la Corte, Toledo } \\
\text { y Campo de Calatrava }\end{array}$ \\
\hline Villanueva de los Infantes & ? & No responde \\
\hline
\end{tabular}

Francisco Javier Campos y Fernández de Sevilla Instituto de Estudios Manchegos Estudios Superiores del Escorial 